\title{
Performance of ductile RC flat slab to steel column connections under cyclic loading
}

\author{
M.A. Eder, R.L. Vollum and A.Y. Elghazouli \\ Department of Civil \& Environmental Engineering \\ Imperial College London, UK
}

\begin{abstract}
:
This paper is concerned with the performance and design of a novel ductile structural steel shearhead for connecting reinforced concrete flat slabs to tubular steel columns. In the suggested system, a gap is left around the column to enable the slab to be connected to the column through isolated structural steel members which are designed to yield in shear before punching failure occurs. The proposed connection could serve as a primary lateral resisting system in regions of moderate seismicity or as a secondary system in areas of significant seismicity. The paper describes a series of large scale slab tests, as well as complementary component tests, which were carried out to develop the proposed shearhead system. The detail is shown to offer enhanced ductility and energy dissipation compared with traditional forms. Experimental and numerical results are used to demonstrate the favourable inelastic performance of the connection under combined gravity and cyclic lateral loading. Finally, recommendations suitable for inclusion in design guidance are presented and discussed for the proposed shearhead detail.
\end{abstract}

Key words: tubular column, flat slab, shearhead, punching shear, ductility, energy dissipation. 


\section{INTRODUCTION}

This paper deals with the design of shearhead systems for connecting reinforced concrete flat slabs to tubular steel columns. ACI 318 [1] gives design guidance for 'fullyintegrated' ACI type shearheads, which is based on the work of Corley and Hawkins [2]. Various proprietary shearhead systems such as the Geilinger mushroom [3] are commercially available for static gravity loading but there is relatively little published research on the generic behaviour of shearhead systems [4-6]. Conventional shearhead systems, such as the ACI-type [1], are "fully integrated" in the sense that the shearhead is entirely cast into the slab. Recent research $[4,6]$ into fully integrated shearheads has focused on increasing shear capacity under static gravity loading through improved composite action achieved by means of shear studs and anchor plates. These systems typically have high punching capacities but low ductility since failure is through punching in the concrete.

This paper describes the final stages in the development of the proposed shearhead (see Figs 1 and 2), which is intended for use in areas of significant seismicity unlike the Geilinger system [3]. The system proposed in this paper (see Figs 1 and 2) is "partially integrated" in the sense that a gap is left around the column to enable the slab to be connected to the column through isolated structural steel members. The detail avoids the uncertainties associated with punching failure by ensuring that the strength of the shearhead system is limited by the isolated structural steel members yielding in shear rather than punching in the slab. Yielding of the steel members in shear is desirable under seismic loading, since it results in high ductility, robust resistance to degradation under cyclic loading, high initial stiffness and significant energy dissipation. This reduces the plastic deformation demand elsewhere in the structure $[7,8]$ and helps to protect the structure from severe structural damage during seismic events. 
The structural form developed incrementally over the course of the research [9-10] during which time three types of shearhead were tested. The initial tests were carried out on a pair of hybrid flat slab specimens with fully embedded ACI type shearheads [9-10] which were tested to failure under i) gravity and ii) combined gravity and cyclic lateral loading. These specimens were similar to the specimen shown in Figs 1 and 2 but without the gap or collar around the column shown in Fig 2. They failed in punching shear and exhibited relatively little ductility under cyclic lateral loading [10]. The design was subsequently modified by leaving a gap around the column (see Fig 1) to enable the exposed length of the shear arms to yield prior to punching failure in the concrete [10]. Initially, the edge around the gap was not reinforced with the collar shown in Fig 2. The tests with this arrangement [10] demonstrated the validity of the gap concept but the performance was impaired by localised concrete failure around the edge of the gap. Therefore, the small scale component tests described in Section 2 were carried out to optimise the connection detail between the shearhead and slab. The results of the component tests were used in conjunction with nonlinear finite element analysis (NLFEA) to develop the shearhead shown in Figs 1 and 2. The resulting shearhead has similarities with the well known Geilinger mushroom system [3] but differs in two fundamental respects which enhance its response under seismic loading. First, the shear arms of the suggested system are designed to yield in shear prior to the concrete failing in punching. Second, the shear arms are extended into the slab to provide axial and rotational restraint to the dissipative zone or "fuse" in the gap. The rotational restraint is beneficial since it halves the characteristic length at which the failure mode of the fuse changes from flexure to shear. The axial restraint allows tensile membrane forces to develop in the shear arms at large displacements, which increases the shear resistance as discussed in Section 5.2. The large scale tests showed that the novel configuration offers significantly more ductility than conventional details in conjunction with stable hysteretic 
behaviour. The tests also showed that the strength of the shearhead system was governed by yielding of the isolated steel members within the gap, which act as dissipative zones or 'fuses', rather than by punching in the slab.

\section{TESTING OF SLAB PANEL COMPONENTS}

This section describes nine panel tests which were carried out to investigate the effectiveness of various shear arm details under cyclic loading. The slab panel (SP) tests provide valuable information on the performance of the shearhead system in large scale tests, including the effects of local concrete failure and low cycle fatigue. Three specimens (SPT11to SPT1-3) were tested under cyclic loading in the first series of panel tests. These specimens were designed to investigate the relative performance of shear arms with open as well as tubular-shaped cross-sections. Test SPT1-3 investigated the effectiveness of casting the edge of the slab into a steel channel to prevent localised shear failure. A further six specimens (SPT2-1 to SPT2-6) were tested in the second series of panel tests which focussed on refining the most promising detail from the first series of tests.

\subsection{Test rig}

The specimen, consisting of a steel shear arm partially embedded in a slab panel, was held within a steel frame which was stressed to the strong floor. The slab was simply supported along its shorter edges between the flanges of channel sections. Pairs of steel wedges were used to secure the specimen between the flanges during cyclic loading. The specimen was connected to a 25 ton actuator via a double hinge which was clamped to the exposed end of the shear arm with a bolted connection (see Fig.1). The load was applied at an 
eccentricity of $85 \mathrm{~mm}$ from the slab edge to the centre line of the ram to make shear action dominant in the shear arms.

\subsection{Specimens and instrumentation}

The size, shape and reinforcement detailing of the slab panels was chosen to be representative of the local conditions around the gap in the large scale slabs. The slab panels measured $900 \times 600 \mathrm{~mm}$ on plan with a thickness of $155 \mathrm{~mm}$. Fig. 3 shows the basic reinforcement layout used in all the tests which consisted of T12 bars at $100 \mathrm{~mm}$ centres in the top layer and T12 bars at $200 \mathrm{~mm}$ centres in the bottom layer. The shear arms were centrally positioned in the slab between the top and bottom reinforcement layers. Tables 1 and 2 give full details of the tested specimens in Series 1 and 2 respectively. The steel properties are given in Table 3. The mean concrete cube strength was $44 \mathrm{MPa}$ in both series of slab panel tests.

The first series of tests compared the performance of shear arms with tubular and I shaped cross sections with the same cross-sectional properties. The tests were designed to examine local shear failure in the concrete. Therefore, the strength of the shear arms was chosen to ensure that failure occurred within the concrete prior to yielding of the shear arms. The tubular sections were $60 \times 100 \times 6.3$ rectangular hollow sections (RHS) which were bent about their minor axis. The I-sections were fabricated from a single $60 \times 100 \times 6.3 \mathrm{RHS}$, by cutting the section in half and welding the two halves back to back. The embedded length of the shear arms in Series-1 was $250 \mathrm{~mm}$. The edge of the slab of specimen SPT1-3 was reinforced with a $500 \mathrm{~mm}$ long $\mathrm{PFC}-150 \times 90 \times 24$ channel section (see Fig. 5a for section dimensions).

The strength of the shear arms was reduced in the second set of tests (see Table 2) to ensure that the shear arms yielded prior to punching failure in the concrete. The shear arms 
were all I sections made from pairs of RSC-51 $\times 38$ hot rolled steel channel $(\mathrm{RSC})$ sections welded back-to-back (see Fig. 5a for section dimensions). Six different connection details were investigated to determine an effective means of reinforcing the slab edge. In all cases, the slab edge was reinforced with a steel channel section to minimise damage to the concrete at the intersection with the shear arm. The tests investigated the necessity of tying the channel section to the slab edge with embedded reinforcement as well as the effect of varying i) the wall thickness of the channel section and ii) the length and end anchorage detail of the embedded shear arm. The aim was to determine the least onerous of these methods of reinforcing the slab edge to prevent localised damage to the concrete.

The front edge of specimens SPT2-1 to SPT2-4 and SPT2-6 were reinforced with a $500 \mathrm{~mm}$ length of PFC $-150 \times 90 \times 24$ channel section as shown in Fig. $3 \mathrm{~b}$. The edge of the remaining specimen SPT2-5 was reinforced with a cold formed C-150 $\times 90 \times 5$ channel section with a constant wall thickness of $5 \mathrm{~mm}$. In tests SPT2-1 and SPT2-3 to SPT2-5, the channel section was connected to the slab edge by welding a pair of $500 \mathrm{~mm}$ long T16 U-bars to the channel web to either side of the shear arm. In tests SPT2-3 and SPT2-6, a 150mm long section of RSC $-51 \times 38$ was welded to the end of the embedded shear arm for anchorage as shown in Fig. 6 . Three $8 \mathrm{~mm}$ diameter stirrups were placed between the ends of the channel section and the adjacent supports as shown in Fig. 4 to strengthen the slab edge in shear.

The applied load was measured with a load cell placed between the actuator ram and the hinge. Strains were measured in the exposed parts of the shear arms with electrical resistance strain gauges. Axial strains were measured in the top and bottom flanges $15 \mathrm{~mm}$ from the slab edge. Shear strains were measured in the web with two rosettes of strain gauges positioned directly opposite each other. Inclinometers were used to measure the rotation at the end of the shear arm and the rotation of the channel edge reinforcement. 


\subsection{Results of Series 1}

The cyclic loading regime followed the ECCS recommendations [11]. The load was applied in displacement control with a constant loading rate of $5 \mathrm{~mm} / \mathrm{min}$. The displacement amplitude was increased from $0.9 \mathrm{~mm}$ in the first cycle to a maximum of $28 \mathrm{~mm}$ unless failure occurred before. The hysteretic response (see Fig. 7a to c) showed extensive degradation and pinching effects from early on. The specimens without edge channels (SPT11 and SPT1-2) failed in punching in the $5^{\text {th }}$ load cycle ( $7 \mathrm{~mm}$ amplitude). The box section (SPT1-1) resisted a peak load of $40 \mathrm{kN}$ compared with $70 \mathrm{kN}$ for the I section (SPT1-2). Shear cracks propagated from the edges of the box section to the nearest concrete surface in Test SPT1-1, but from the tips of the flanges to the furthest concrete surface in Test SPT1-2 with the I section. The shear cracks were oriented at between 30 and $40^{\circ}$ to the horizontal. The higher strength of SPT1-2 is explained by the relatively deeper punching cone observed in test SPT1-2 compared with SPT1-1 (see Fig. 5c). Specimen SPT1-3 with channel edge reinforcement resisted a peak load of around $135 \mathrm{kN}$. The pre-peak performance was governed by transverse beam action which was limited by the shear strength of the slab edge between the ends of the channel reinforcement and the supports. Diagonal shear cracks formed in the unreinforced part of the slab edge as shown in Fig. 8 for specimen SPT2-3 which was typical. The cracks widened significantly with increasing displacement. The shear resistance of the unreinforced slab edge reduced significantly in the post-peak regime during which the load was increasingly transferred into the slab through mechanical interlock between the channel and the slab edge.

\subsection{Results of Series 2}

Table 4 and Figs. 9a to f summarise the performance of the specimens in Series-2. Comparison of the peak loads for SPT2-1, SPT2-4 and SPT2-6 in Table 4 shows that the peak load and ductility were significantly increased by the addition of the welded U-bars. 
Comparison of the performances of SPT2-4 (with welded U bars and a $250 \mathrm{~mm}$ long shear arm) and SPT2-2 (with a $340 \mathrm{~mm}$ long shear arm) shows that increasing the embedment length alone was not as effective as using U-bars to anchor the channel to the slab edge. The U-bars were effective since they prevented the channel from separating from the slab edge thereby minimising damage to the slab edge. The flanges of the thinner channel used in SPT2-5 were less effective at controlling the deterioration of the slab edge at the intersection with the shear arm than the thicker channel used in the other tests. Fig. 9 also shows that specimen SPT-3 with welded U bars and end anchorage performed most favourably.

\subsection{Comparative assessment}

As observed in the tests and discussed above, the cyclic behaviour of the shear arm details without channel edge reinforcement is unsuitable for dissipative seismic design due to local concrete degradation and pinching effects. Tubular sections were also found to be less effective for shear arms than I sections due to the reduced depth of the shear cone punched out of the concrete at failure (see Fig 4c). Specimen SPT1-3, with edge reinforcement, behaved more favourably than SPT1-1 and SPT1-2, without edge reinforcement, since the channel distributed the load into the slab edge and restrained its expansion due to cracking. Furthermore, the edge channel provided an alternative path for transferring shear force into the slab. The behaviour was further improved when i) welded $U$ bars were used to connect the edge channel to the slab and ii) an anchor plate was welded to the end of the shear arm. Both measures increased shear resistance by controlling the width of the through-thickness crack that developed at the tips of the flanges of the channel reinforcing the slab edge. The SPT2-3 detail behaved most favourably out of all the investigated details. This can be seen by comparing Figs. 5b and 7c which show the hysteretic responses of shear arm SPT1-2 without channel edge reinforcement and SPT2-3 with channel edge reinforcement, respectively. The shear resistance of SPT2-3 was 2.8 times greater than that of SPT1-2 and the displacement at 
the peak load was three times greater in test SPT2-3 than SPT1-2. The slab panel tests showed that detail SPT2-3 was most suitable for use in the large scale slab tests.

\section{TESTING OF LARGE SCALE SLAB-TO-COLUMN-ASSEMBLAGES}

The objective of the experimental study was to compare the performance of the proposed partially embedded shearhead with that of the comparable ACI type shearheads tested previously by the authors under gravity [9] and combined gravity and cyclic lateral loading [10]. Two large scale specimens were tested in this programme to determine the loaddisplacement response of the partially embedded shearhead under firstly, pure gravity, and secondly, combined gravity and cyclic lateral loading. Each slab was connected to a tubular steel column with a shearhead based on the SPT2-3 detail. The failure loads of the specimens are summarised in Table 6.

\subsection{Test rig}

A purpose-built test rig was used to test slabs under uni-directional lateral cyclic loading conditions with co-existing gravity loads. As illustrated in Fig. 8, the test rig consists of the following main parts:

- A 25t reaction frame connected to the strong floor via 9 prestressed bolts

- A $25 \mathrm{t}$ horizontal actuator $( \pm 125 \mathrm{~mm}$ stroke $)$ connected to the reaction frame and the top of the column stub via clevises.

- Eight symmetrically arranged pin ended vertical restraints which connect the slab edges to the strong floor.

- A 100t vertical hydraulic jack connected to the bottom of the column stub, sharing the same hinge with the 'tie member' restraining the base of the column. 
- The test specimen which is connected to the upper and lower tubular steel column stubs via bolted head plates.

The lateral displacement can be applied either monotonically or cyclically. The horizontal actuator was used in displacement control in all the tests, whereas the vertical actuator was used in load control. Loads were measured with load cells positioned between the hydraulic rams and the hinges at the respective column ends.

\subsection{Specimen details}

The interior slab-to-column assemblages were constructed at $60 \%$ of full scale. The dimensions of the tested slabs were identical to those of the conventional ACI-type shearheads tested by the authors previously $[9,10]$. The slabs measured $2880 \mathrm{~mm} \times 2440 \mathrm{~mm}$ on plan between the centrelines of the vertical restraints in the "longitudinal" and "transverse" directions respectively. The slab depth was $155 \mathrm{~mm}$. The column measured 1185 $\mathrm{mm}$ between the midpoints of the hinges at the top and bottom of the stub column. The reinforcement layout is shown in Fig. 9. The reinforcement consisted of T12 bars in each direction with the top and bottom reinforcement spaced at centres of $100 \mathrm{~mm}$ and $200 \mathrm{~mm}$ respectively, all with a minimum cover of $20 \mathrm{~mm}$. Bundled reinforcement bars were placed adjacent to the edges of the hole, to compensate for the bars that were discontinued across the width of the opening. Additional U-bent bars were used to trim the edges of the opening as well as the slab edges.

The shearhead assembly consisted of a continuous column fabricated from a square hollow section (SHS) of size $180 \times 10 \mathrm{~mm}$ and shear arms made of RSC-51×38 hot rolled steel channel sections welded back-to-back (see Fig. 2). The shear arms were welded to the column via $8 \mathrm{~mm}$ thick polygonal shaped gusset plates $(366 \times 366 \mathrm{~mm})$ fillet-welded to the top and bottom of the channel sections. The gusset plates were designed to smoothly transfer 
forces into the column from the flanges of the shear arms and to prevent yielding of the column. The welds of the detail used for cyclic testing were aligned parallel to the axial strain direction to minimise the effect of extremely low cycle fatigue (ELCF). A full depth collar made from a PFC- $150 \times 90 \times 24$ section was used to trim the $500 \times 500 \mathrm{~mm}$ square opening in the slab (see Fig. 2). Each shear arm passed through an opening cut in the web of the collar, and was welded to the collar through a $15 \mathrm{~mm}$ thick stiffener plate. The distance between the edge of the gusset plate and the centreline of the web of the collar was $70 \mathrm{~mm}$. Tee shaped anchor pieces and welded U-bars (see Fig. 2) were used as in the SPT2-3 detail described previously. The shearhead was centrally embedded between the four layers of reinforcement. The shear arms are identified with the prefixes "longitudinal" or "transverse", with the longitudinal shear arms oriented parallel to the direction of the imposed lateral displacement.

The slab was cast from ready-mix concrete with a maximum aggregate size of $\mathrm{d}_{\max }=10 \mathrm{~mm}$. The specimens were cured under plastic sheets during the first week after casting. Control specimens were cured in air alongside the slabs and in water at $20^{\circ} \mathrm{C}$. The concrete strengths were measured on the day of testing. The mean concrete cube strength was $47 \mathrm{MPa}$ and the mean concrete splitting tensile strength was 3.1 $\mathrm{MPa}$. Tensile tests were carried out on the reinforcement bars. Longitudinal strains were measured with a clip gauge extensometer (gauge length $100 \mathrm{~mm}$ ), and stresses were evaluated for the nominal cross section. Four necked coupons were cut from samples of the RSC-51×38 channel sections used for the shear arms in the large scale slab tests. Displacements were measured with a optical extensometer over a gauge length of $50 \mathrm{~mm}$. Table 3 gives average mechanical properties for the reinforcement and shear arms. The structural steel properties were obtained according to BS EN 10002-1 [12]. Stress-strain diagrams are given elsewhere [9] for the reinforcement and shear arms. 


\subsection{Instrumentation}

Vertical displacements were measured with LVDT's at the centre of the slab and with string pot extensometers attached to the collar below the slab. Horizontal displacements of the column head were measured directly within the actuator. The horizontal slab displacements were measured with LVDT's located at the front edge of the slab. Strains were measured in one longitudinal and one transverse shear arm within the gap using electrical resistance strain gauges. Axial strains were measured in the top flanges with gauges positioned $15 \mathrm{~mm}$ from the edge of the gusset plate and $12 \mathrm{~mm}$ from the web of the collar. Shear strains were measured with strain gauge rosettes positioned midway along the fuse at the centre of the web. Radial and tangential concrete surface strains were measured with a Demec mechanical extensometer.

\subsection{Gravity loading test (Specimen LS-1)}

In this test, the gravity load was increased in $30 \mathrm{kN}$ increments to $570 \mathrm{kN}$, which was the maximum safe working load of the test rig. There were no signs of imminent punching failure when the test was stopped. Fig. 11 shows the crack pattern at the end of Test LS-1 while Fig. 12 depicts the gravity load versus central deflection. The figure also shows the comparative response with that of the fully integrated ACI type shearhead tested by the authors previously [9]. Hair line cracks appeared at the top surface of the slab at the corners of the collar at $90 \mathrm{kN}$ and propagated radially. Cracks developed along the edge of the collar at $150 \mathrm{kN}$. Circumferential cracks appeared over the anchors at the end of the shear arms at $320 \mathrm{kN}$.

A Demec gauge was used to measure the radial and circumferential strains in the top surface of the slab over the shearhead arms. At $500 \mathrm{kN}$, the maximum recorded circumferential strain was 0.0040 over the longitudinal shear arm at a distance of $140 \mathrm{~mm}$ 
from the collar edge. The corresponding peak radial strain was 0.0038 at the tip of the longitudinal shear arm. The cracks closed almost completely when the slab was unloaded, indicating that little if any plastic deformation developed within the reinforcement during the test.

The axial strain in the top flanges of the shear arms reached the yield limit of 0.0015 at around $250 \mathrm{kN}$ when the central displacement was $8 \mathrm{~mm}$. The strain increased gradually as the load was increased to $375 \mathrm{kN}$. Thereafter, the axial strain increased rapidly to 0.033 as the load was increased to $570 \mathrm{kN}$ at which load the central displacement was $32 \mathrm{~mm}$. The web yielded in shear at around $375 \mathrm{kN}$ when the central displacement was $15 \mathrm{~mm}$. The shear strain was 0.025 at the end of the test when the differential displacement between the edge of the gusset plate and the collar was $8 \mathrm{~mm}$.

\subsection{Lateral cyclic loading test (Specimen LS-2)}

The specimen was initially loaded with a gravity load of $200 \mathrm{kN}$ which was maintained throughout the test. The gravity load was chosen to be the same as that adopted in the lateral load test of the companion specimen $\mathrm{H} 1$ which was reinforced with a fully embedded ACI type shearhead. It is also representative of the design gravity load under seismic loading as it is around half the load at which the shear arms yielded in shear under gravity loading in test LS-1. Subsequently, the specimen was loaded with cyclic lateral displacements which followed the ECCS [11] recommendations as shown in Fig. 13. The displacement amplitudes in the ECCS loading recommendations are linear functions of the lateral yield displacement under monotonic loading. The yield displacement is defined as the displacement at the intersection of a line drawn through the origin with slope $\mathrm{E}_{0}$ (where $\mathrm{E}_{0}$ is the initial stiffness) and a line with slope $\mathrm{E}_{1}=\mathrm{E}_{0} / 10$ drawn tangential to the load displacement curve. The yield displacement was estimated with NLFEA to be $e_{y}=15 \mathrm{~mm}$ for specimen H1. This 
displacement was subsequently used to define the amplitude of the lateral loading displacements used in all the cyclically loaded tests. The peak lateral displacement was limited to $80 \mathrm{~mm}$ in cycles 11 to 13 of the test by the actuator stroke length. A constant loading rate of $10 \mathrm{~mm} / \mathrm{min}$ was used throughout.

The crack pattern developed under gravity loading as described in Section 3.4. The cracks propagated radially towards the edges of the specimen as the lateral displacement was increased. Fig. 14a shows that the lateral load versus displacement response was both ductile and stable unlike that of the comparable ACI type shearhead [10] shown in Fig. 14b. Fig. 15 shows the evolution of axial strain in the top flanges of the longitudinal and transverse shear arms adjacent to the gusset plates. Fig. 15 shows that the strains remained just within the elastic limit of 0.0015 in the transverse shear arms, whereas extensive yielding occurred in the longitudinal arms where failure initiated in the $11^{\text {th }}$ cycle. The fillet welds connecting the longitudinal shear arm to the gusset plate visibly fractured in the $13^{\text {th }}$ cycle. The failure of the welds caused the load resistance to drop in successive cycles as the fracture in the welds extended along the flange edges with the parent material remaining intact. The top gusset plate eventually completely separated from the flange. The test was stopped after 15 load cycles when the lateral load resistance had deteriorated by $23 \%$. The peak lateral load was $F_{x}$ $=70 \mathrm{kN}$ which induced a bending moment of $83 \mathrm{kNm}$ into the slab. The corresponding peak column drift was $6.8 \%$.

\subsection{Comparative assessment of proposed and ACI type shearheads}

Fig. 12 compares the load displacement response in Test LS-1 with that of a fully integrated ACI type shearhead previously tested by the authors [9]. The specimens were virtually identical apart from the gap around the column in Test LS-1. Fig. 12 shows that punching resistance in Test LS-1, which was not reached, exceeded that of the ACI type 
shearhead tested previously [9] by at least 25\%. The authors [10] also tested the ACI type shearhead H1 described in [9], under the cyclic lateral loading shown in Fig. 13 acting in conjunction with a gravity load of $200 \mathrm{kN}$. Comparison of Figs. 14a and 14b shows that the peak lateral load of $70 \mathrm{kN}$ in Test LS-2 is similar to that of $76 \mathrm{kN}$ for the comparable ACI type shearhead H1 [10]. Fig. 14 also shows that the load-displacement response of the partially integrated shearhead (LS-2) was far more ductile than that of the comparable ACI type shearhead. The partially integrated shearhead dissipated $15.7 \mathrm{~kJ}$ of energy which is around five times that dissipated by the ACI type shearhead. The cyclic lateral loading tests showed that the behaviour of the partially integrated shearhead was almost entirely governed by the response of the isolated shear arms within the gap as intended.

\section{NUMERICAL ANALYSES}

\subsection{General}

Numerical simulations were carried out to determine the contribution of the shearhead to the shear strength of the tested specimens. The analyses investigated the mechanics of load transfer within the shearhead. The results of these analyses were used to develop the design oriented analytical procedure presented in Section 5. The analysis was carried out using the finite element program DIANA v9.3 [13]. Concrete was modelled with 20 noded isoparametric brick elements and the structural steel sections with 8 noded isoparametric curved shell elements. Reinforcement was modelled with 3 noded 3D cable elements. A full $3 \times 3 \times 3$ integration scheme was adopted for the solid elements within the zone of mesh refinement. A $2 \times 2 \times 2$ reduced integration scheme was used elsewhere. A $3 \times 3 \times 7$ integration scheme was used for the shell elements with 7 integration points through the depth of the element. The reinforcement was modelled as perfectly elasto-plastic. A tri-linear hardening 
diagram was used to simulate the measured stress-strain response of the shearhead [9] in the gravity load test. On the other hand, bi-linear strain hardening was used to model the cyclic hardening which occurred in test LS-2. The hardening was taken as $0.75 \%$ up to the ultimate strength after which the strength remained constant with increasing strain. Perfect bond was assumed between the reinforcement and the embedded structural steel elements. Concrete was modelled with a total strain model based on the modified compression field theory of Vecchio et al. [14] and its 3-D extension by Selby and Vecchio [15]. The concrete compressive behaviour was described with the parabolic hardening and softening relationship proposed by Feenstra [16]. In the present analysis, the fracture energy in compression was taken $G_{c}=100 G_{f}$ where $G_{f}$ denotes the fracture energy in tension, which was calculated in accordance with MC90 [17]. A smeared fixed crack model was used in conjunction with the Rankine failure criterion. For the concrete tensile behaviour exponential tension softening was used. The crack bandwidth $h$ was taken as $h=\sqrt[3]{V}$ (V=volume of the element). A constant shear retention factor $\beta$ was used to model the reduction in shear stiffness after cracking. The material parameters adopted in the NLFEA are summarised in Table 5 in which the concrete cylinder strength is taken as $\mathrm{f}_{\mathrm{c}}{ }^{\prime}=0.8 \mathrm{f}_{\text {cube }}$ in accordance with MC90 [18]. The background to the choice of the material parameters is discussed elsewhere [10].

The load was applied in displacement control for pure gravity loading. On the other hand, load control was used for gravity loading and displacement control for lateral loading for combined loading. The lateral load was applied monotonically in the analysis of test LS-2 even though the specimen was cyclically loaded. A quasi (secant method) Newton solution procedure was adopted. The iteration was terminated when the energy norm was less than or equal to $10^{-3}$. The results of the NLFEA are summarised in Table 6 and discussed below. 


\subsection{Simulation of gravity load test LS-1.}

Fig. 12 compares the measured and predicted load displacement responses for the gravity load test LS-1. Results are presented for the actual fuse length of $70 \mathrm{~mm}$ with (baseline analysis) and without geometric nonlinearity. Strain hardening is not included in any of the analyses discussed below or Fig. 12 unless noted otherwise as it made very little difference to the results due to the long yield plateau of the shear arms. This is illustrated for the baseline analysis which is presented in Fig. 12 with and without strain hardening. The analyses were terminated when the peak extreme fibre strain in the fuse reached $\varepsilon_{\mathrm{xx}}=0.25$ which is just less than the minimum fracture strain measured in the coupon tests of the parent metal which was 0.31 . Fig. 12 shows that the baseline analysis agrees well with the measured response. Geometric nonlinearity is seen to become significant at around $400 \mathrm{kN}$ when the deflections calculated with and without geometric nonlinearity diverge. The slight underestimate in the predicted displacements is attributed to the analysis overestimating the degree of composite action between the slab and the shearhead.

The following discussion refers to the baseline analysis with geometric nonlinearity. The shearhead first yielded in the top flanges of the longitudinal shear arms, adjacent to the collar reinforcing the slab edge, at $180 \mathrm{kN}$ compared with $250 \mathrm{kN}$ in the test. The reinforcement first yielded at $315 \mathrm{kN}$ in the transverse bars at the corners of the collar. The yielding of these bars had little if any effect on the predicted central displacement. The webs of the shear arms yielded in shear at $430 \mathrm{kN}$, which is the capacity calculated in the first order analysis, compared with around $380 \mathrm{kN}$ in the test. Thereafter, the resistance increased significantly due to geometric nonlinearity as shown in Fig. 12.

Fig. 16 shows the plastic axial strain contours $\varepsilon_{\mathrm{pxx}}$ at the peak load superimposed onto the shearhead in its deflected shape. The strain contours show concentrations of localised 
axial strain at the ends of the fuse. Figs. 17, 18 and 19 show the distribution of shear force, axial force and bending moment distribution in the shear arms at the elastic limit and at the predicted failure load of $615 \mathrm{kN}$. The axial forces, shear forces and bending moments were

obtained by integration as follows: $N=\int_{A} \sigma \cdot d A, V=\int_{A} \tau d A$ and $M=\int_{A} \sigma \cdot z d A$ where $A$ is the cross-sectional area of the shear arm. Fig. 17 shows that the shear force is largely transferred into the shear arm at the collar rather than along the embedded length of the arm. Fig. 18 shows that significant axial forces develop in the shear arms if properly anchored with end plates or otherwise. The end plates are likely to have been more effective in the test than suggested by Fig. 18 since the shear arms were assumed to be perfectly bonded to the concrete in the analysis. Fig. 19 shows that the maximum bending moment in the shear arm was $3 \mathrm{kNm}$ which is significantly less than the flange plastic moment capacity of $6.1 \mathrm{kNm}$ due to the effect of local flange bending.

The analysis was repeated with fuse lengths of $45 \mathrm{~mm}$ and $90 \mathrm{~mm}$. The analyses were stopped when the peak extreme fibre strain in the fuse reached 0.025 as in the analyses of LS1. The length of the fuse was varied by changing the diameter of the gusset plate around the column. Fig. 12 shows that the increase in resistance due to geometric nonlinearity increased as the length of the fuse was reduced.

\subsection{Simulation of lateral load test LS-2.}

The first order lateral resistance was calculated to be $F_{x}=45 \mathrm{kN}$ in test LS-2 which corresponds to a bending moment of $53 \mathrm{kNm}$ in the slab. Fig. 20 compares the backbone of the hysteretic response with the predicted responses including geometrical nonlinearity. Comparison with the backbone, suggests that geometric nonlinearity and strain hardening 
increased the first order lateral resistance by a factor of 1.6. Furthermore, the lateral resistance was significantly underestimated if hardening was neglected. The following discussion refers to the baseline analysis with hardening unless stated otherwise. Tensile yielding was first predicted to occur at $F_{x}=8 \mathrm{kN}$ (where $F_{x}$ is the lateral load applied to the column) in the left hand longitudinal shear arm of Fig. 8 at the intersection between the top flange and the collar around the column. The web was predicted to yield completely in shear at $F_{x}=18 \mathrm{kN}$ causing the stiffness of the load displacement response to soften. Subsequently, the shear force in the right hand fuse reduced more rapidly as $F_{x}$ increased, reversing direction when $F_{x}$ reached $20 \mathrm{kN}$. The first order capacity of $F_{x}=45 \mathrm{kN}$ was reached when the right hand web yielded in shear at a lateral displacement of $19 \mathrm{~mm}$. At this point, the top flange of the right hand fuse was in tension whereas the bottom flange was in compression. Both flanges were in tension when the analysis was stopped at the peak lateral displacement imposed in the test of $80 \mathrm{~mm}$. The corresponding peak strain in the shear arms was 0.25 at the intersection of the left hand shear arm of Fig. 8 with the gusset plate around the column.

Fig. 20 also shows the influence of fuse length on the calculated load displacement response. The fuse length was varied by changing the size of the gusset plate as described in Section 4.1. All the analyses were terminated when the peak strain in the top flange of the critically loaded shear arm reached 0.25 as in the analysis of LS-2. Reducing the fuse length to $45 \mathrm{~mm}$, from $70 \mathrm{~mm}$ in the test, increased the stiffness of the response as expected. The capacity of the $45 \mathrm{~mm}$ fuse is $14 \%$ greater than that of the $70 \mathrm{~mm}$ fuse but its ductility is $37 \%$ less. Conversely, the $90 \mathrm{~mm}$ fuse has a $16 \%$ lower capacity than the $70 \mathrm{~mm}$ fuse but $18 \%$ greater ductility. 


\section{DESIGN CONSIDERATIONS}

In order to achieve high ductility, local buckling should be prevented in the shear arms, or significantly delayed, through the adoption of plastic cross-sections [18] and the provision of transverse stiffeners if necessary. The shearhead resistance can be split into its first and second order capacities with the latter being dependent on displacement. Second order effects can be neglected when calculating the design resistance of the shearhead system under seismic loading. On the other hand, the slab should be designed to resist the greatest possible moment that can be transferred into it from the shearhead, including its second order response, to comply with capacity design requirements such as that stipulated in EC8 (Clause 2(P) of Section 2.2.4.1) [19,20].

\subsection{First order response}

The first order capacity can be calculated with plastic analysis using the collapse mechanisms shown in Fig. 21 in which the plastic deformation is assumed to be confined to the fuses. The external loads are assumed to be applied at the centreline of the column. The flexural resistance of the fuses is governed by their plastic moment capacity, taking due account of the interaction with shear. The plastic shear resistance $R$ is governed by the interaction between flexure and shear which depends on the fuse length $L$. The latter is assumed to equal the distance from the outside edge of the gusset plate, around the column, to the centreline of the web of the channel reinforcing the edge of the gap. The failure mode switches from flexure to shear when the length of the hinge reduces below its characteristic length $L_{c h}$ which is given by equation (1). The flanges undergo localised flexural deformations at the ends of the fuse when the web deforms plastically in shear. This creates plastic hinges in the flanges which increases the plastic web capacity of the fuse, as described in previous studies on similar behaviour in column panel zones [8], with the enhancement in 
strength becoming increasingly significant as the fuse length decreases. The shear resistance $R$ of each shear hinge is given by equation (2), in which the second term represents the contribution from flange bending taking due account of the coexisting axial force due to flexure.

$L_{c h}=\frac{2 \sqrt{3} w t_{f}}{t_{w}}$

$R=V_{p l}+w f_{y}\left(\frac{t_{f}^{2}}{L}-\frac{t_{w}^{2} L}{12 w^{2}}\right)$

where $t_{f}$ is the flange thickness; $t_{w}$ is the web thickness; $L$ is the fuse length which is $70 \mathrm{~mm}$ for LS- 1 and LS- $2 ; w$ is the width of the flange; $h$ is the depth between the centrelines of the flanges; $V_{p l}=h t_{w} f_{y} / \sqrt{3}$ is the plastic web capacity and $f_{y}$ is the nominal yield strength. Equations (3) to (6) below depict the shearhead capacities for each of the four collapse mechanisms shown in Fig. 21 where Mode I represents the gravity load case.

Mode I: $F_{z}=4 R: \quad M_{y}^{I}=0$

Mode II: $3 R+V_{p l}<F_{z} \leq 3 R: \quad M_{y}^{I I}=M_{p l(Q)}+R\left(4 L_{R}+3.5 L\right)-F_{z}\left(L_{R}+L\right)$

Mode III: $3 R<F_{z} \leq 3 R-V_{p l}: \quad M_{y}^{I I I}=M_{p l(Q)}+0.5 R L+4 R L_{R}-F_{z} L_{R} \leq M_{y}^{I V}$ at $F_{z}=2 R$

Mode IV: $2 R<F_{z} \leq 0$ :

$M_{y}^{I V}=2 R L_{R}+R L+2 M_{t, r d-w}+2 M_{t, r d-N}$

where $F_{z}$ is the gravity load from the slab, $M_{y}$ is the maximum moment that can be transferred from the column into the slab and $L_{R}$ is the length of the rigid link (see Fig. 21) which is 170 $\mathrm{mm}$ for the tested specimens LS-1 and LS-2. The flexural resistance $M_{p l(Q)}$ of the least loaded longitudinal fuse in Modes II and III depends on the coexisting shear force $Q=F_{z}-3 R$ as described by equation (7). Linear interpolation can be used between Mode I and Mode II and 
between the end of Mode III and Mode IV. The torsional resistance of the transverse shear arms is included in Mode IV, where it is defined in terms of the direct $\left(M_{t, r d-N}\right)$ and warping $\left(M_{t, r d-N}\right)$ torsional resistances in the absence of gravity loading. $M_{t, r d-N}$ is given by equation (8) which can be derived using the sand heap analogy [21]. $M_{t, r d-N}$ is given by equation (9) [22], which is based on the assumption that flexural hinges form in the flanges at the ends of the fuse where warping is restrained. The torsional resistance is assumed to reduce linearly to zero as $F_{v}$ is increased from zero to $2 R$.

$$
\begin{aligned}
& M_{p l(Q)}=f_{y} w h t_{f}+t_{w}\left(\frac{h}{2}\right)^{2} \sqrt{f_{y}^{2}-3\left(\frac{Q}{h t_{w}}\right)^{2}} \\
& M_{t, r d-N}=\frac{f_{y}}{\sqrt{3}}\left[w t_{f}^{2}+\frac{h t_{w}^{2}}{2}\right]\left[\frac{2 R-F_{v}}{2 R}\right] \\
& M_{t, r d-w}=f_{y} \frac{t_{f} h w^{2}}{2 L}\left[\frac{2 R-F_{v}}{2 R}\right]
\end{aligned}
$$

\subsection{Geometric nonlinearities and ductility demands}

Geometric nonlinearity induces tensile forces into the fuses which enhance the system capacity above that calculated with first order analysis. The second order shear resistance $R_{2}$ of the fuses can be estimated in terms of their angular displacement as follows:

$$
R_{2}=V_{p l}+w f_{y} \frac{t_{f}^{2}}{L}-\frac{V_{p l}^{2} L}{4 h^{2} w f_{y}}-\frac{\sigma^{2} w t_{f}^{2}}{L f_{y}}+N \sin \gamma
$$

where $N$ is the tensile force in the fuse, $\gamma$ is its angular displacement, $\sigma=$ N/A where $A$ is the cross-sectional area of the fuse and $V_{p l}$ is the plastic web shear capacity in the presence of $N$ which is given by: 
$V_{p l}=h t_{w} \sqrt{\frac{\sigma_{y}^{2}-\sigma^{2}}{3}}$

The peak angular displacement $\gamma_{\max }$ of the shear hinges in the longitudinal shear arms can be calculated in terms of the specified drift ratio $D_{R}$ and the shearhead geometry with equations (12) to (14).

Mode II: $\gamma_{\max }^{I I}=\frac{D_{R}\left(2 L_{R}+L\right)}{L}$

Mode III: $\gamma_{\max }^{I I I}=\frac{D_{R}\left(2 L_{R}\right)}{L}$

Mode IV: $\gamma_{\max }^{I V}=\frac{D_{R} L_{R}}{L}$

The ductility demand is satisfied if $\gamma_{\max } \leq \gamma_{u}$ where $\gamma_{u} \approx \frac{\Delta_{u f u s e}}{L}$, in which $\Delta_{u f u s e}$ is the vertical displacement between the ends of the fuse at failure. $\gamma_{u}$ was 0.18 in test LS-2 for which $\sin \gamma \approx \gamma$. The second order load resistances $F_{z}$ and $M_{y}$ corresponding to modes I to IV can be estimated with equations (15) to (18) which are derived from considerations of equilibrium. Linear interpolation can be used between Modes I and II and between Modes III and IV. The angular displacements $\gamma$ are assumed to be the same in both the longitudinal and transverse shear hinges in modes II and III to simplify the analysis. This assumption is conservative in the sense that it increases the maximum moment that can be transferred into the slab.

Mode I: $F_{z 2}=4 R_{2}: \quad M_{y 2}^{I}=0$

Mode II: $3 R_{2}+V_{p l}<F_{z 2} \leq 3 R_{2}: M_{y 2}^{I I}=M_{p l(Q)}+R_{2}\left(4 L_{R}+3.5 L\right)-F_{z 2}\left(L_{R}+L\right)+0.5 N L \gamma$ 
Mode III: $3 R_{2}<F_{z 2} \leq 3 R_{2}-V_{p l}$ :

$$
M_{y 2}^{I I I}=M_{p l(Q)}+0.5 R_{2} L+4 R_{2} L_{R}-F_{z 2} L_{R}+0.5 N L \gamma \leq M_{y}^{I V} \text { at } F_{z}=2 R_{2}
$$

Mode IV: $2 R_{2}<F_{z 2} \leq 0: \quad M_{y 2}^{I V}=2 R_{2} L_{R}+R_{2} L+N L \gamma+2 M_{t, r d-w}+2 M_{t, r d-N}$

in which:

$$
\begin{aligned}
& M_{p l(Q)}=\left(f_{y}-\sigma\right) w h t_{f}+t_{w}\left(\frac{h}{2}\right)^{2} f_{\text {yeff }}-\frac{t_{w} h^{2} \sigma^{2}}{4 f_{\text {yeff }}} \quad \text { for } \mathrm{Q}=\mathrm{F}_{\mathrm{z}}-3 \mathrm{R}_{2} \leq \mathrm{V}_{\mathrm{pl}} \\
& f_{\text {yeff }}=\sqrt{f_{y}^{2}-3\left(\frac{Q}{h t_{w}}\right)^{2}}
\end{aligned}
$$

Table 7 compares the predictions of the first and second order analytical models with those of NLFEA, with and without geometric nonlinearity at various gravity loads. The limiting rotation $\gamma_{\max }$ was taken as 0.18 radians in the analytical method as this was the value measured at failure in test LS-2. The axial force $N$ in equation (10) was chosen by trial and error to maximise the shear resistance $R_{2}$ for $\gamma=0.18$. The resulting value of $\mathrm{N}$ was $256 \mathrm{kN}$ which compares very favourably with the value of around $265 \mathrm{kN}$ shown in Fig. 18. All the predictions neglect the effect of strain hardening as well as material over-strength, yet it is assumed that these would be captured by the strength factors adopted in capacity design procedures. The limiting angular displacement of 0.18 radians measured in test LS-2 is rather greater than the limit of 0.08 radians typically suggested for short links in eccentrically braced frames [20]. Therefore, it is suggested that in the absence of better information $\gamma_{u}$ is taken as 0.08 radians when considering drift limits for the proposed shearhead system. On the other hand, it is suggested that $\gamma_{u}$ should be taken as 0.18 radians when calculating the second 
order moment resistance of the shearhead system as this provides an upper bound to the moment transferred into the slab.

Fig. 22 shows the interaction between the flexural and gravity load resistances calculated with the first (equations (3) to (6)) and second order analytical relations (equations (15) to (18)). The figure includes relevant test data as well as the results from the NLFEA which was carried out to verify the analytical procedure. The NLFEA and the analytical model underestimate the measured strength of the connection since strain hardening was not considered as discussed previously. Therefore, the predictions of the analytical model should be compared with the NLFEA. The analytical model is seen to underestimate the first order moment capacity under lateral loading which is conservative for the design of the shearhead. On the other hand, the second order analytical model gives very good estimates of the moment capacities predicted by NLFEA for the range of $F_{z}$ likely to arise under seismic loading despite remaining largely conservative for unrealistically low or high values of $\mathrm{F}_{\mathrm{z}}$.

\subsection{Punching shear capacity}

The punching shear capacity of the proposed shearhead system cannot be definitively established since punching failure did not occur in the tested specimens LS-1 and LS-2. Furthermore, the contribution of the shear arms to the shear strength is uncertain since the shear arms did not act as cantilever beams as in the fully embedded ACI-type shearhead tested previously [9]. This is illustrated in Figs. 17 and 18 which show that the primary functions of the embedded length of the shear arms in the proposed detail are to rotationally restrain the arm at its intersection with the collar (see Fig. 18) and to provide tensile anchorage, rather than to collect shear forces from the slab. It is therefore recommended that the embedded length of the shear arm should be neglected when calculating the critical shear perimeter. 
The shear strength of the connection was estimated using the recommendations of Chana and Birjandi [6] as previously implemented by the authors [9]. The shear resistance under concentric gravity loading was calculated as $V_{\text {out }}=v_{r d c} U_{l} d$ where $v_{R d c}$ is the basic shear resistance given by EC2 [23] which is $1.16 \mathrm{MPa}$ for the tested slabs (with $\gamma_{c}=1$ where $\gamma_{c}$ is the partial factor for concrete), $d$ is the mean effective slab depth and $U_{l}$ is the critical shear perimeter. The design shear stress $v_{E d}$ under eccentric loading was calculated in accordance with equation 6.38 in EC2 as follows:

$v_{E d}=\beta \frac{V_{E d}}{U_{1} d}$

In which

$\beta=1+k \frac{M_{E d}}{V_{E d}} \frac{U_{1}}{W_{1}}$

where $k=0.6$ in this case since the effective column is square, $M_{E d}$ is the moment transferred into the column and $W_{1}$ is the first moment of area of the shear perimeter $U_{1}$ about its centroid.

$U_{l}$ was calculated neglecting the shear arms since their contribution to shear resistance is uncertain as discussed above. The shear perimeter was consequently assumed to be a square perimeter of length $U_{l}$ located at $1.25 \mathrm{~d}$ from the outer perimeter of the collar as suggested previously $[6,9]$. The length $U_{l}$ and first moment of area $W_{l}$ of the critical shear perimeter are given by equations (31) and (32) respectively.

$U_{1}=4 l_{c}+10 d$

$W_{1}=\frac{3\left(l_{c}+2.5 d\right)^{2}}{2}$ 
where $l_{c}$ denotes the outmost collar edge length of $680 \mathrm{~mm}$ and $d$ denotes the mean effective slab depth which was $123 \mathrm{~mm}$ for slabs LS-1 and LS-2.

The punching resistance was calculated to be $563 \mathrm{kN}$ under concentric gravity loading which is only slightly smaller than the peak load of $570 \mathrm{kN}$ applied in test LS-1 which was insufficient to cause failure. The moment required to induce punching failure under a coexistent gravity load of $250 \mathrm{kN}$ was calculated to be $194 \mathrm{kNm}$ which is significantly greater than the maximum applied moment of $83 \mathrm{kNm}$. Slightly greater, but still reasonable, estimates of punching resistance are obtained with EC2 if calculated for a square column with sides of length $l_{c}$ (i.e. $680 \mathrm{~mm}$ square). In this case, the punching resistance is calculated to be $609 \mathrm{kN}$ under concentric gravity loading which is slightly greater than the peak load of 570 $\mathrm{kN}$ applied in test LS-1. This suggests that the shearhead increased the effective column size to at least the outer dimensions of the shearhead in tests LS-1 and LS-2. This conclusion is further supported by the fact that a peak load of $215 \mathrm{kN}$ was measured in slab panel test SPT2-3 in which the same edge channel, welded U bars and shear arm detail was used as in tests LS-1 and LS-2. Slab panel test SPT2-5, with welded U bars, suggests that the punching capacity would not have been significantly affected by reducing the section thickness of the edge channel to $5 \mathrm{~mm}$ but this would need to be confirmed with further testing.

\section{CONCLUSION}

This paper proposes a shearhead system for connecting reinforced concrete flat slabs to steel columns. The system incorporates a novel detail in which a gap is left in the slab around the column to enable the isolated shear arms to yield in shear before punching failure occurs within the slab. The system is shown by testing and numerical analysis to provide favourable performance under both gravity and cyclic loading in comparison with 
conventional fully embedded ACI-type shearheads. Nonlinear finite element analysis showed that the lateral resistance of the connection is significantly increased by cyclic strain hardening of the shear arms. The experimental and numerical findings were used to develop design considerations and recommendations. The shear arms should be designed to yield in shear within the gap before the slab fails in punching. The slab-panel component tests showed that I-sections perform better as shear arms than closed box sections due to improved composite action with the slab. The shear arms should be anchored to the concrete with end plates or otherwise to resist the significant axial forces which arise as a result of geometric nonlinearity. The edge of the opening in the slab around the column should be reinforced with a steel channel which should be tied into the slab with welded U bars or similar details. Low cycle fatigue should also be considered in the design of the welding details. In order to satisfy the requirements of capacity design, a procedure for evaluating the dependable strength as well as over-strength of the system was proposed and discussed.

\section{ACKNOWLEDGEMENTS}

The financial support of Corus and CIDECT for the tests described in this paper is gratefully acknowledged. The authors are grateful to Mr Andrew Orton of Corus Tubes for his technical support to the project. The authors would also like to thank the technical staff of the Structures Laboratories at Imperial College London, particularly Mr. R. Millward, for their assistance with the experimental work.

\section{REFERENCES}

1 ACI 318-08, Building Code Requirements for Structural Concrete and Commentary, 
American Concrete Institute 2008, Farmington Hills.

2 Corley WG and Hawkins NM, Shearhead Reinforcement for Slabs, ACI Structural Journal 1968; 65(10), 811-824.

3 Geilinger (1986), 'Geilinger Stahlpilze zur Verstaerkung von Flachdecken im Stuetzenbereich', Institut fuer Bautechnik Z-4.6-95, 8.

4 Piel W, Zur Erhoehung der Durchstanztragfaehigkeit von Flachdecken mit Stahlverbundsystemen, PhD thesis, Bergische Universitaet Wuppertal; 2004.

5 Chana PS and Birjandi FK, Design guidance on structural steel shearheads in concrete, Project report for Reinforced Concrete Council and Department of the Environment, CRIC CLIENT REPORT CRIC95/001/F, Imperial College London, 1996.

6 Fastabend, M., Sauerborn, N., Neubauer, T. \& Doering, N. 'Concepts of composite constructions for high punching loads - basic principles and application', Beton- Und Stahlbetonbau 2008, 103(11), 735-740.

7 Chan, R.W.K, Albermani, F., Williams, M.S., Evaluation of yielding shear panel device for passive energy dissipation, Journal of Constructional Steel Research 2009, $65(2) ; 260-268$.

8 Castro J. M., Davila-Arbona F. J., and A. Y. Elghazouli. Seismic design approaches for panel zones in steel moment frames. Journal of Earthquake Engineering 2008, 12 (1): $34-51$.

9 Eder MA, Vollum RL, Elghazouli AY, and Abdel-Fattah T, Modelling and Experimental Assessment of Punching Shear in Flat Slabs with Shearheads, Engineering Structures 2010, 32(12): 3911-3924. 
10 Eder M, Elghazouli AY and Vollum RL, Strength and Ductility of Connections between Tubular Columns and Flat Slabs under Monotonic and Cyclic Loading Conditions, CIDECT Programme 4F, Final Report, Imperial College London, June 2010.

11 ECCS. European Convention for Constructional Steelwork. Recommended Testing Procedure for Assessing the Behaviour of Structural Steel Elements under Cyclic Loads. Brussels, 1986.

12 BS EN 10002-1, Metallic materials - Tensile testing - Part1: Method of test at ambient temperature, British Standards Institution, 2001.

13 DIANA, User's manual Material Library, Release 9.3, May 2008.

14 Vecchio FJ, and Collins MP, The Modified Compression-Field Theory for Reinforced Concrete Elements Subjected to Shear, ACI Journal 1986, 83(2): 219-231.

15 Selby RG, and Vecchio FJ, A constitutive model for analysis of reinforced concrete solids, Canadian Journal of Civil Engineering 1997, 24: 460-470.

16 Feenstra P H, Computational Aspects of Biaxial Stress in Plain and Reinforced Concrete., PhD thesis, Delft University of Technology, 1993.

17 Comite Euro International du Beton CEB. CEB-FIB Model Code 1990: Design Code. Thomas Telford, 1990.

18 EN1993-1-1:2005, Eurocode 3: Design of steel structures-General rules and rules for buildings, EN 1993-1-1: 2005 (E) European Committee for Standardisation, CEN, Brussels, 2005. 
19 EN1998-1-2004. Eurocode 8, Design of structures for earthquake resistance, Part 1: General rules, seismic actions and rules for buildings, European Committee for Standardisation, CEN, Brussels, 2004.

20 Elghazouli AY (Editor), Seismic design of buildings to Eurocode 8, Taylor and Francis, 2009.

21 Nadai A., Plasticity. McGraw-Hill, New York-London, 1931.

22 Dinno KS, Gill SS, The plastic torsion of I-sections with warping restraints, International Journal of Mechanical Science 1964, 6(1): 27-43.

23 British Standards Institution, European Standard EN-1992-1-1:2004, Eurocode 2: Design of Concrete Structures. Part 1, General Rules and Rules for Buildings, British Standards Institution, 2004, London. 


\begin{tabular}{|c|c|c|c|c|}
\hline Specimen & $\begin{array}{c}\text { Shear arm } \\
\text { length }\end{array}$ & Shear arm & $\begin{array}{c}\text { Edge } \\
\text { reinforcement }\end{array}$ & $\begin{array}{c}\text { Peak load } \\
{[\mathrm{kN}]}\end{array}$ \\
\hline SPT1-1 & $250 \mathrm{~mm}$ & $\begin{array}{c}60 \times 100 \times 6.3 \\
\text { RHS }\end{array}$ & - & 40 \\
\hline SPT1-2 & $250 \mathrm{~mm}$ & $\mathrm{I}^{\#}$ & - & 70 \\
\hline SPT1-3 & $250 \mathrm{~mm}$ & $\mathrm{I}^{\#}$ & $\begin{array}{c}\text { PFC- } \\
150 \times 90 \times 24\end{array}$ & 135 \\
\hline
\end{tabular}

Note: ${ }^{\#}$ Fabricated from $60 \times 100 \times 6.3$ RHS

Table 1: Properties and failure loads for Series $1 \mathrm{slab}$ panel tests

\begin{tabular}{|c|c|c|c|c|}
\hline Specimen & $\begin{array}{c}\text { Shear } \\
\text { arm } \\
\text { length }\end{array}$ & Edge reinforcement & $\begin{array}{l}\text { Welded } \\
\text { U-bars }\end{array}$ & Anchor \\
\hline SPT2-1 & $150 \mathrm{~mm}$ & PFC-150x90x24 & 2T16 U bars & No \\
\hline SPT2-2 & $340 \mathrm{~mm}$ & PFC-150x90x24 & No & No \\
\hline SPT2-3 & $250 \mathrm{~mm}$ & PFC-150x90x24 & 2T16 U bars & Yes $\dagger$ \\
\hline SPT2-4 & $250 \mathrm{~mm}$ & PFC-150x90x24 & 2T16 U bars & No \\
\hline SPT2-5 & $250 \mathrm{~mm}$ & C-150x90x5 cold f. & 2T16 U bars & No \\
\hline SPT2-6 & $250 \mathrm{~mm}$ & PFC-150x90×24 & No & Yest \\
\hline
\end{tabular}

Note: ${ }^{\#}$ Fabricated from pairs of RSC-51 $\times 38$ hot rolled steel channel (RSC) sections welded back-to-back. $\uparrow 150 \mathrm{~mm}$ long section of RSC-51×38

Table 2: Properties for Series 2 slab panel tests 


\begin{tabular}{|l|c|c|c|c|}
\hline \multicolumn{1}{|c|}{ Specimen } & $\mathrm{E}_{0}$ & $\sigma_{02}$ & $\sigma_{\mathrm{u}}$ & $\varepsilon_{\mathrm{L}}$ \\
\hline- & {$[\mathrm{GPa}]$} & {$[\mathrm{MPa}]$} & {$[\mathrm{MPa}]$} & - \\
\hline T12 rebar & 200 & 552 & 617 & 0.14 \\
\hline RHS 100x60x6 & 198 & 405 & 484 & 0.27 \\
\hline RSC-51x38 & 210 & 300 & 401 & 0.41 \\
\hline
\end{tabular}

Note: $\sigma_{02}$ is the $0.2 \%$ proof stress, $\varepsilon_{\mathrm{L}}$ is the percentage elongation at fracture

Table 3: Mean steel properties for shear arms and reinforcement

\begin{tabular}{|c|c|c|c|c|c|}
\hline Specimen & $\mathrm{F}_{\mathrm{p}}$ & $\mathrm{e}_{\mathrm{p}}$ & $\mathrm{F}_{\mathrm{p}} / \mathrm{F}_{\mathrm{u}}$ & $\mathrm{e}_{\mathrm{p}} / \mathrm{e}_{\mathrm{y}}$ & $\mathrm{F}_{\mathrm{deg}}$ \\
\hline & {$[\mathrm{kN}]$} & {$[\mathrm{mm}]$} & {$[1]$} & {$[1]$} & {$[\%]$} \\
\hline SPT2-1 & 195 & 15.75 & 1.47 & 4.85 & 20 \\
\hline SPT2-2 & 175 & 14.00 & 1.97 & 2.07 & 25 \\
\hline SPT2-3 & 215 & 18.75 & 1.25 & 4.83 & 27 \\
\hline SPT2-4 & 212 & 15.12 & 1.75 & 3.02 & 19 \\
\hline SPT2-5 & 205 & 13.87 & 1.60 & 2.46 & 22 \\
\hline SPT2-6 & 123 & 14.25 & 1.76 & 7.58 & 28 \\
\hline
\end{tabular}

Note: $F_{p}$ denotes the peak load, $F_{u}$ denotes the load at the ultimate displacement of $28 \mathrm{~mm}, \mathrm{e}_{\mathrm{p}}$ denotes the peak displacement, $\mathrm{e}_{\mathrm{y}}$ is the yield displacement as stipulated in [5] and $\mathrm{F}_{\text {degr }}$ is the degradation of the peak load.

Table 4: Strength and ductility for Series 2 slab panel tests 


\begin{tabular}{|c|c|c|c|c|c|c|c|}
\hline $\mathrm{f}_{\mathrm{c}}{ }^{\prime}$ & $\mathrm{f}_{\mathrm{t}}$ & $\mathrm{f}_{\mathrm{y}-\mathrm{sh}}$ & $\mathrm{f}_{\mathrm{y}-\mathrm{rt}}$ & $\varepsilon_{\mathrm{c}}$ & $\mathrm{E}_{\mathrm{c}}$ & $\mathrm{G}_{\mathrm{f}}$ & $\beta$ \\
\hline$[\mathrm{MPa}]$ & {$[\mathrm{MPa}]$} & {$[\mathrm{MPa}]$} & {$[\mathrm{MPa}]$} & - & {$[\mathrm{MPa}]$} & {$\left[\mathrm{mJ} / \mathrm{mm}^{2}\right]$} & - \\
\hline 38 & 1.5 & 300 & 560 & 0.003 & 21075 & 0.067 & 0.1 \\
\hline
\end{tabular}

Note: $f_{c}{ }^{\prime}=$ concrete uniaxial compressive strength, $f_{t}=$ concrete tensile strength, $f_{y-s h}=$ yield strength of shearhead, $f_{y-r f t}=$ yield strength of reinforcement, $\varepsilon_{c}=$ strain at peak concrete stress, $E_{c}=$ elastic modulus for concrete, $G_{f}=$ tensile fracture energy, $\beta=$ shear retention factor.

Table 5: Material properties used in NLFEA

\begin{tabular}{|c|c|c|c|c|c|c|c|c|c|}
\hline Specimen & $\mathrm{F}_{\mathrm{z} \text { test }}$ & $\mathrm{F}_{1 \mathrm{z} \mathrm{n}}$ & $\mathrm{F}_{2 \mathrm{zn}}$ & $\mathrm{M}_{\text {test }}$ & $\mathrm{M}_{\mathrm{n}}^{1}$ & $\mathrm{M}_{\mathrm{n}}^{2}$ & $\mathrm{M}_{\mathrm{n}}^{2 \mathrm{~h}}$ & $\mathrm{DR}_{\text {test }}$ & $\mathrm{DR}_{\mathrm{n}}$ \\
\cline { 2 - 10 } & {$[\mathrm{kN}]$} & {$[\mathrm{kN}]$} & {$[\mathrm{kN}]$} & {$[\mathrm{kNm}]$} & {$[\mathrm{kNm}]$} & {$[\mathrm{kNm}]$} & {$[\mathrm{kNm}]$} & {$[\%]$} & {$[\%]$} \\
\hline LS-1 & $570 \dagger$ & 430 & 615 & 0 & 0 & - & - & - & - \\
\hline LS-2 & 200 & 200 & 200 & 83 & 53 & 61 & 83 & 6.8 & 6.8 \\
\hline
\end{tabular}

Notes: $F_{z}=$ gravity load, indices ' 1 ', ' 2 ' and ' $2 \mathrm{~h}$ ' depict first and second order results with (h) and without strain hardening respectively, indices 'test' and ' $n$ ' depict 'measured' and 'numerical' results, $\mathrm{DR}=$ drift ratio, $\dagger$ denotes that the test was stopped before failure when the applied load equalled the rig capacity.

Table 6: Comparison of measured and predicted response of LS slab tests 


\begin{tabular}{|c|c|c|c|c|c|c|c|c|}
\hline $\mathrm{F}_{\mathrm{z}}$ & $\mathrm{M}_{\mathrm{a}}^{1}$ & $\mathrm{M}_{\mathrm{n}}^{1}$ & $\mathrm{M}_{\mathrm{a}}^{1} / \mathrm{M}_{\mathrm{n}}^{1}$ & $\mathrm{M}_{\mathrm{a}}^{2}$ & $\mathrm{M}_{\mathrm{n}}^{2}$ & $\mathrm{M}_{\mathrm{a}}^{2} / \mathrm{M}_{\mathrm{n}}^{2}$ & $\mathrm{DR}_{\mathrm{a}}$ & $\mathrm{DR}_{\mathrm{n}}$ \\
\hline$[\mathrm{kN}]$ & {$[\mathrm{kNm}]$} & {$[\mathrm{kNm}]$} & {$[1]$} & {$[\mathrm{kNm}]$} & {$[\mathrm{kNm}]$} & {$[1]$} & {$[\%]$} & {$[\%]$} \\
\hline 0 & 52.6 & 58 & 0.91 & 66.6 & 73 & 0.91 & 7.0 & 7.7 \\
\hline 200 & 44.0 & 53 & 0.83 & 59.7 & 62 & 0.96 & 7.0 & 6.8 \\
\hline 300 & 30.9 & 40 & 0.77 & 46 & 46 & 1.00 & 3.5 & 4.0 \\
\hline 400 & 4.7 & 17 & 0.28 & 28.5 & 27 & 1.06 & 2.9 & 3.3 \\
\hline
\end{tabular}

Notes: $F_{z}=$ gravity load, indices ' 1 ' and ' 2 ' depict first and second order results respectively all without strain hardening, indices ' $a$ ' and ' $n$ ' depict 'analytical' and 'numerical' results, $\mathrm{DR}=$ drift ratio for $\gamma_{\max }=0.18$.

Table 7: Comparison of numerical and analytical predictions of shearhead performance under lateral loading 

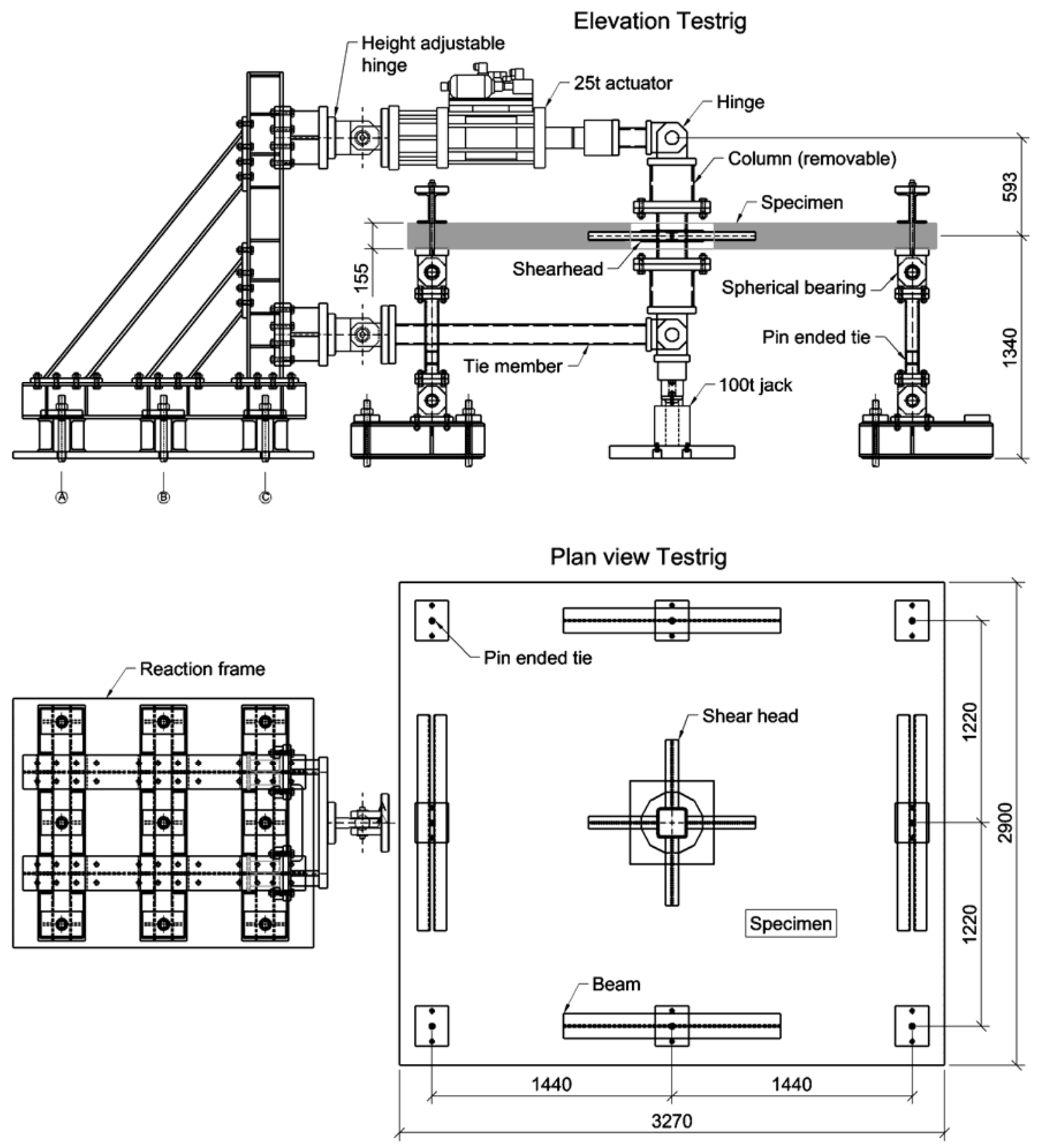

Figure 1: Test rig used for large scale tests 

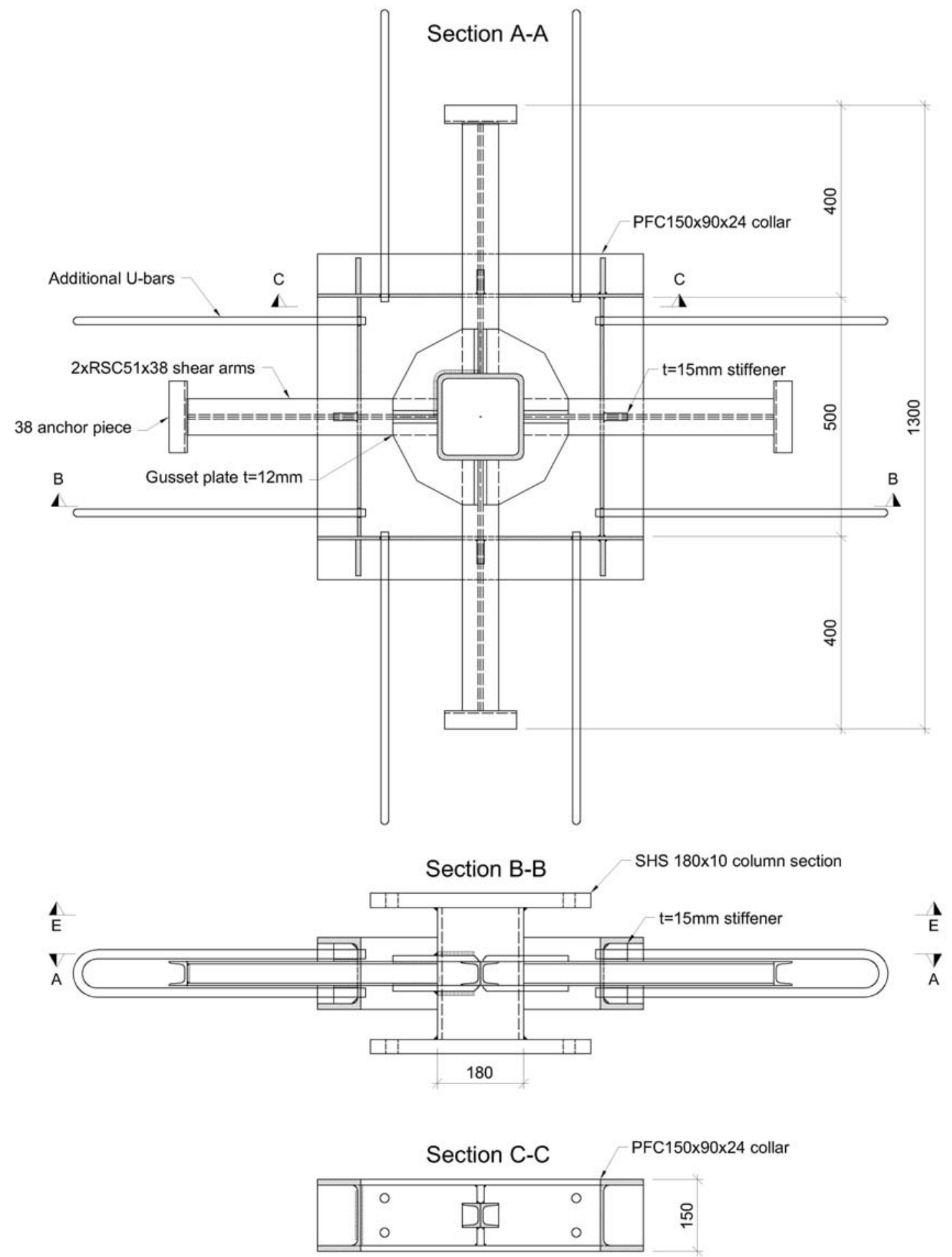

Figure 2: Shearhead used in tests LS-1 and LS-2 

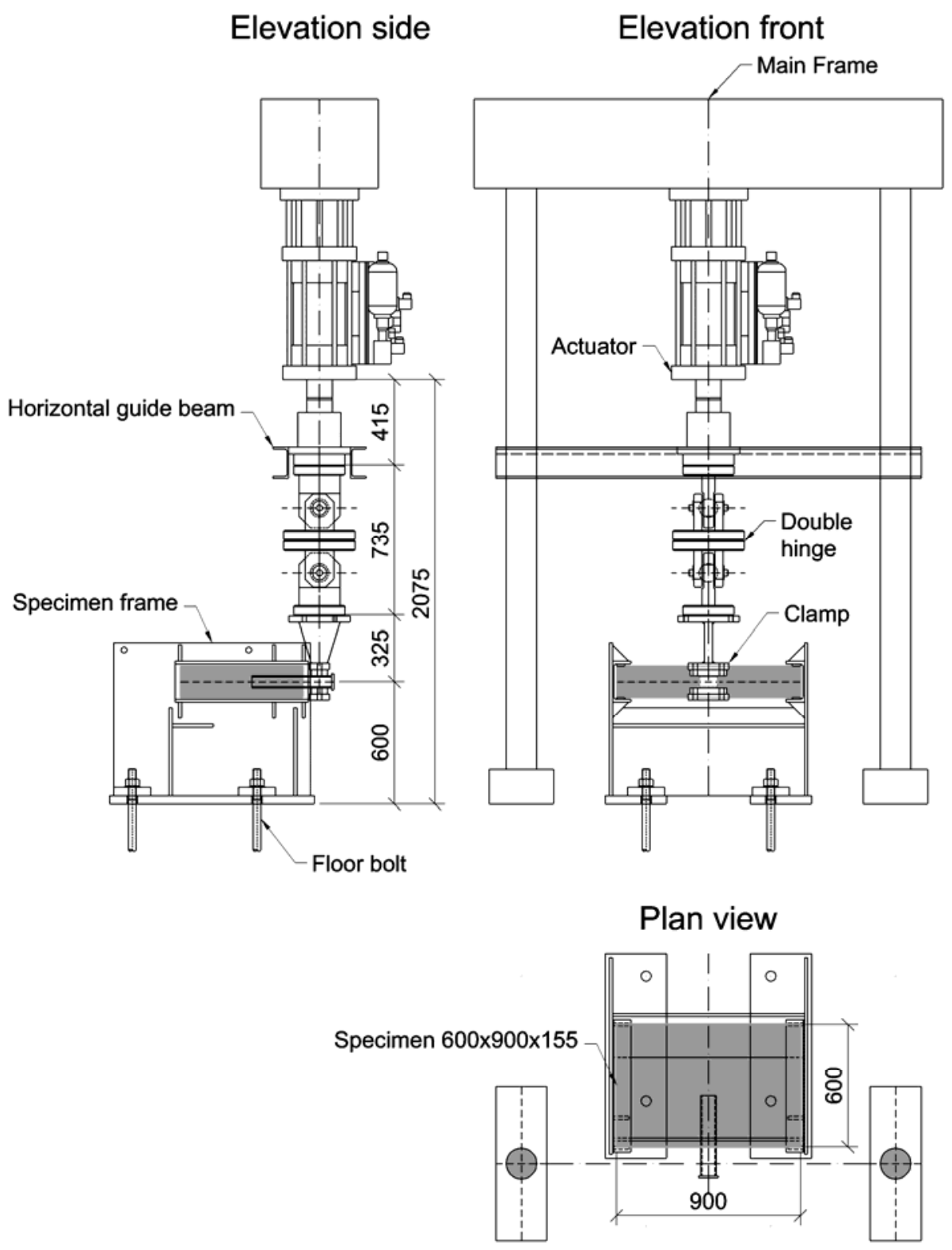

Figure 3: Slab panel test rig 
Top Reinforcement
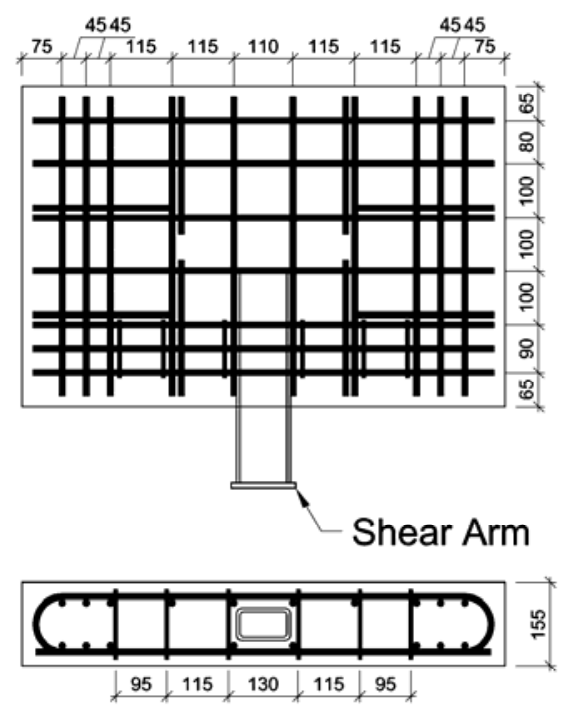

Additional stirrups present in Series-2 only

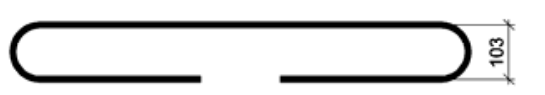

848

\section{Bottom Reinforcement}
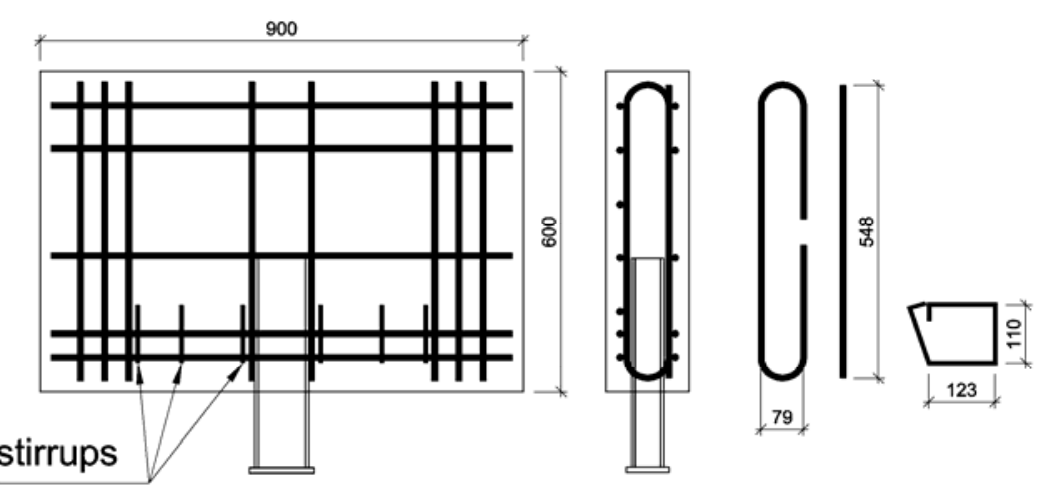

Shear arm shown is RHS

but also applies for I-section

Main reinforcement all $\mathrm{H} 12$ bars

Stirrups all $\mathrm{H} 8$ bars

Minimum cover $25 \mathrm{~mm}$ (except above stirrups)

Figure 4: Details of slab panel specimens (drawn with box section and no edge channel) 


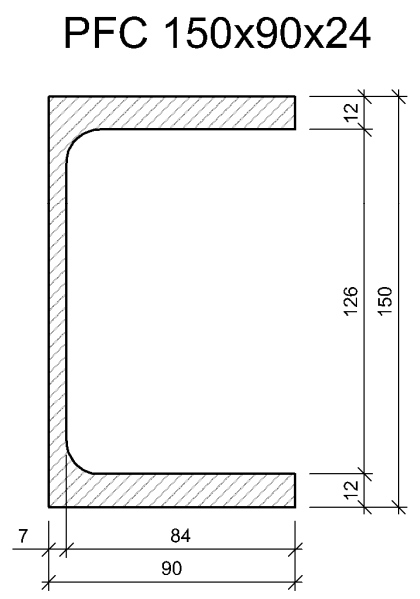

RHS $60 \times 100 \times 6.3$

(split and welded back-to-back)

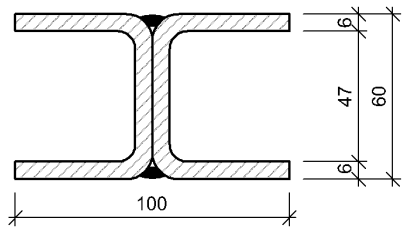

RSC $51 \times 38$

(welded back-to-back)

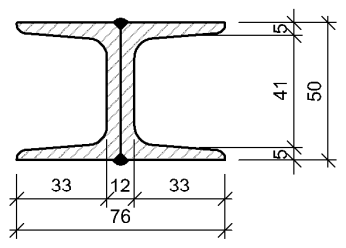

Figure 5a: Details of steel sections used in slab panel specimens
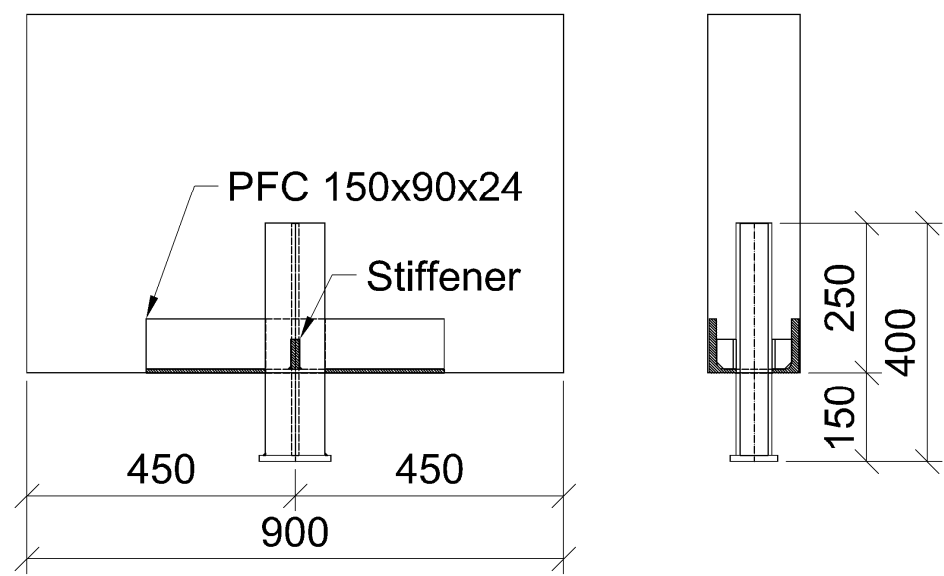

RHS 60x100x6.3 (Series-1)

RSC 51×38 (Series-2)

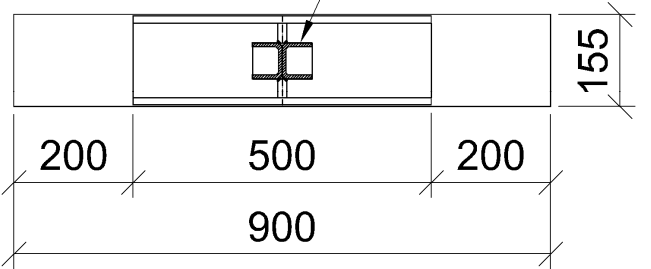

Figure 5b: Plan view and cross-section of slab panel specimen with edge channel 
Failure cones for I-section

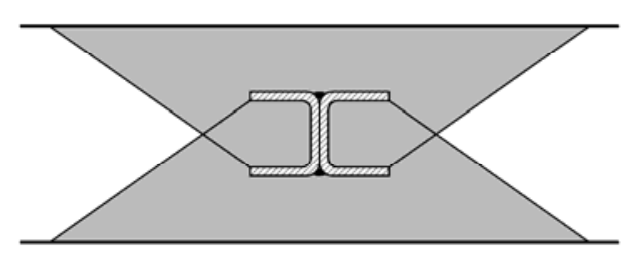

Failure cones for box section

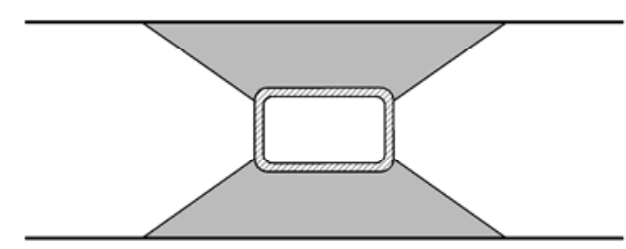

Figure 5c: Comparison of concrete failure cones for box and "I" sections. 


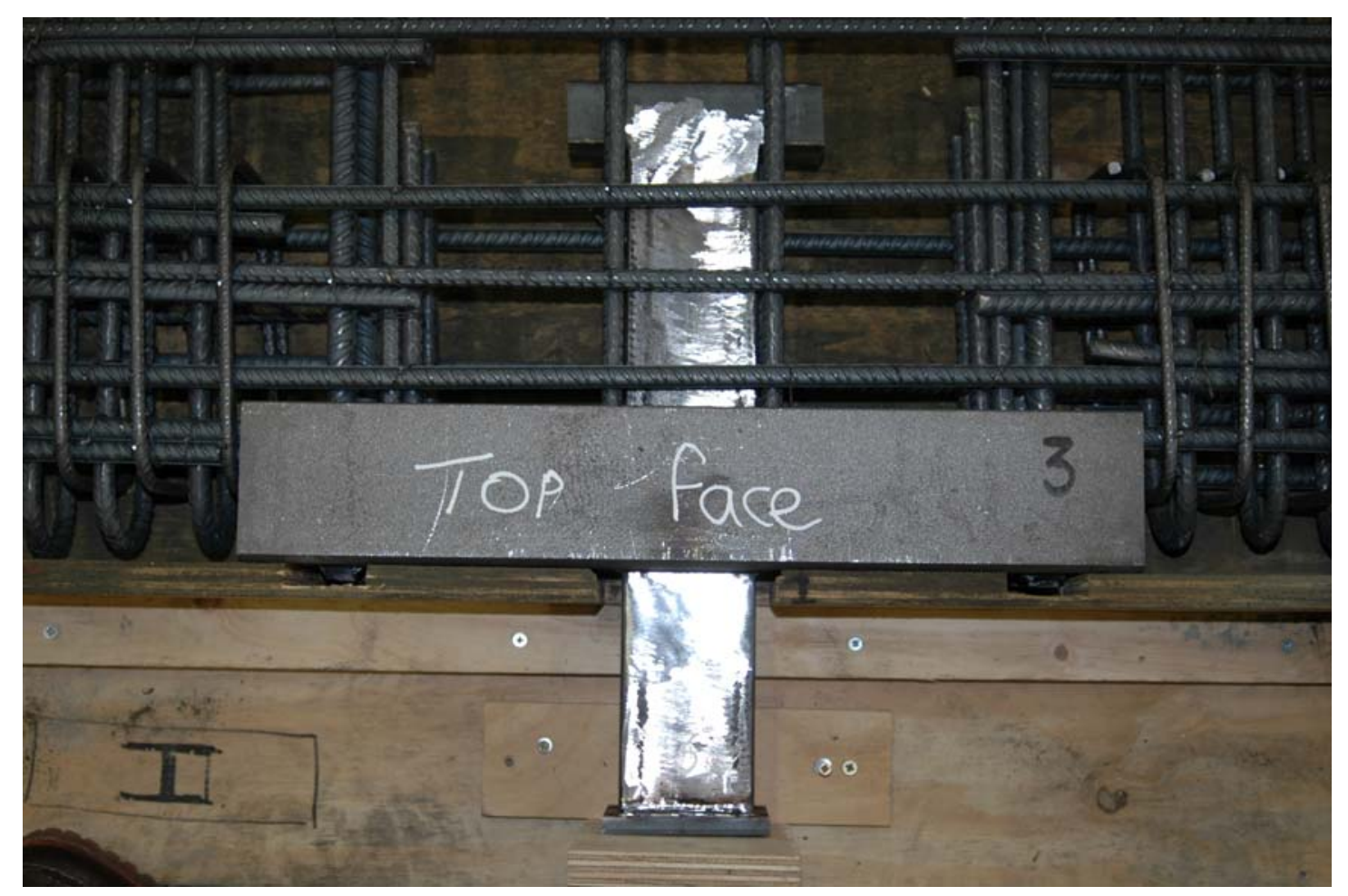

Figure 6: SPT2-3 detail with main reinforcement prior to casting 
a)

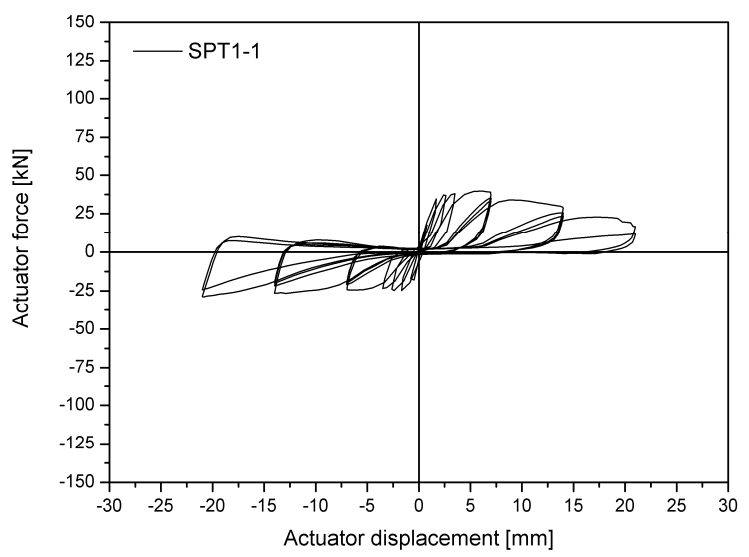

c)

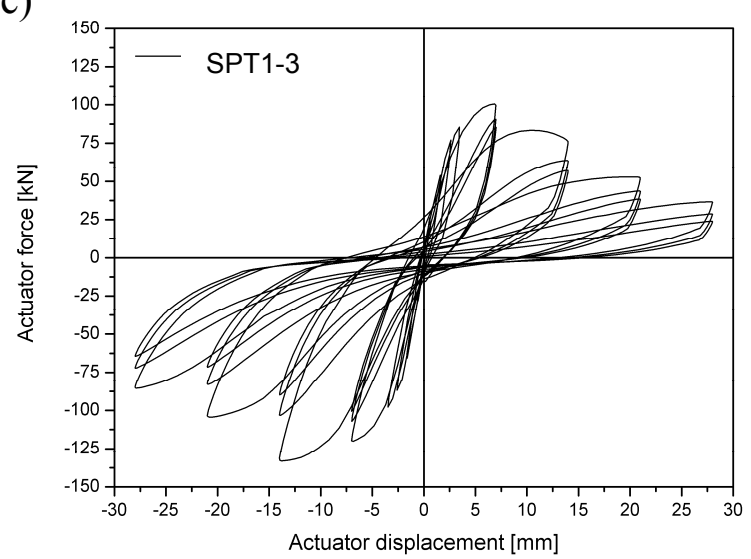

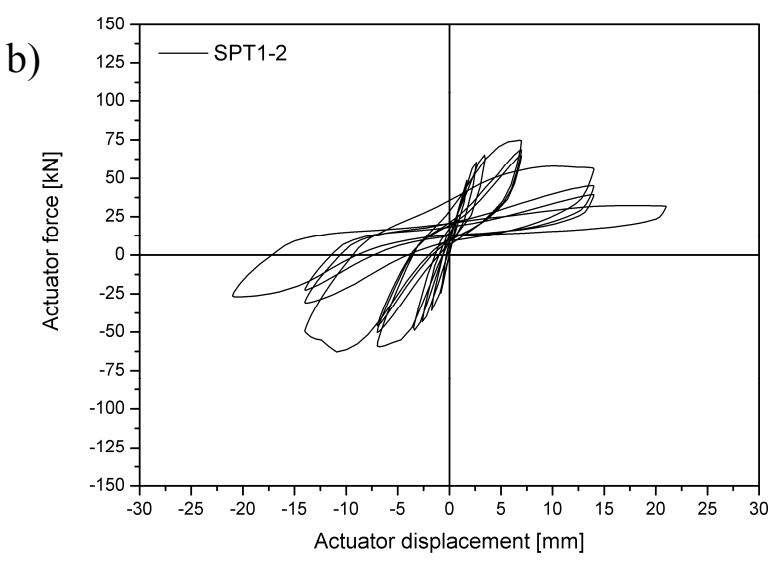

Figure 7: Hysteretic response of slab panel tests; a) SPT1-1, b) SPT1-2, c) SPT1-3. 


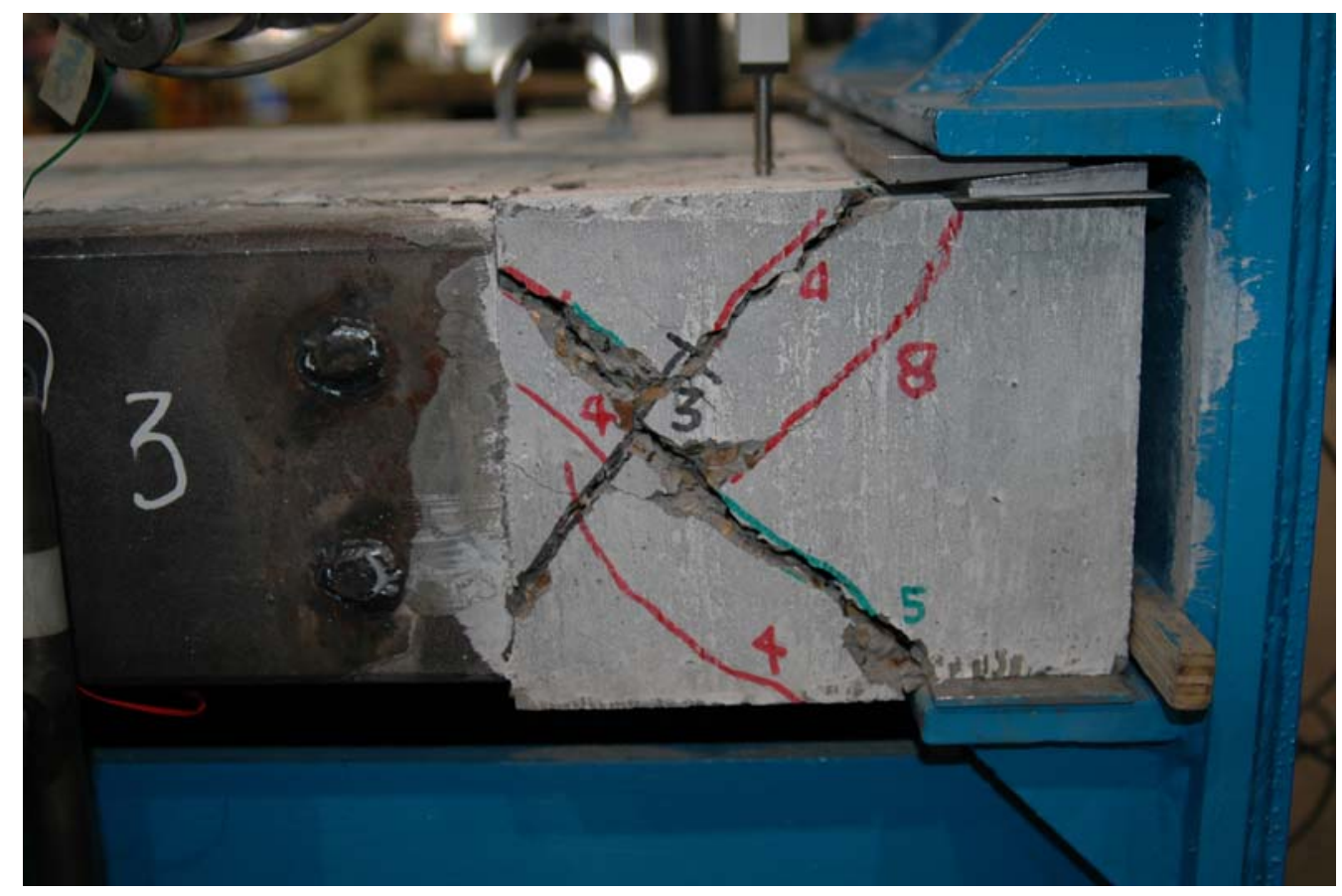

Figure 8: Shear cracking in front face of slab panel adjacent to edge channel in test SPT2-3 

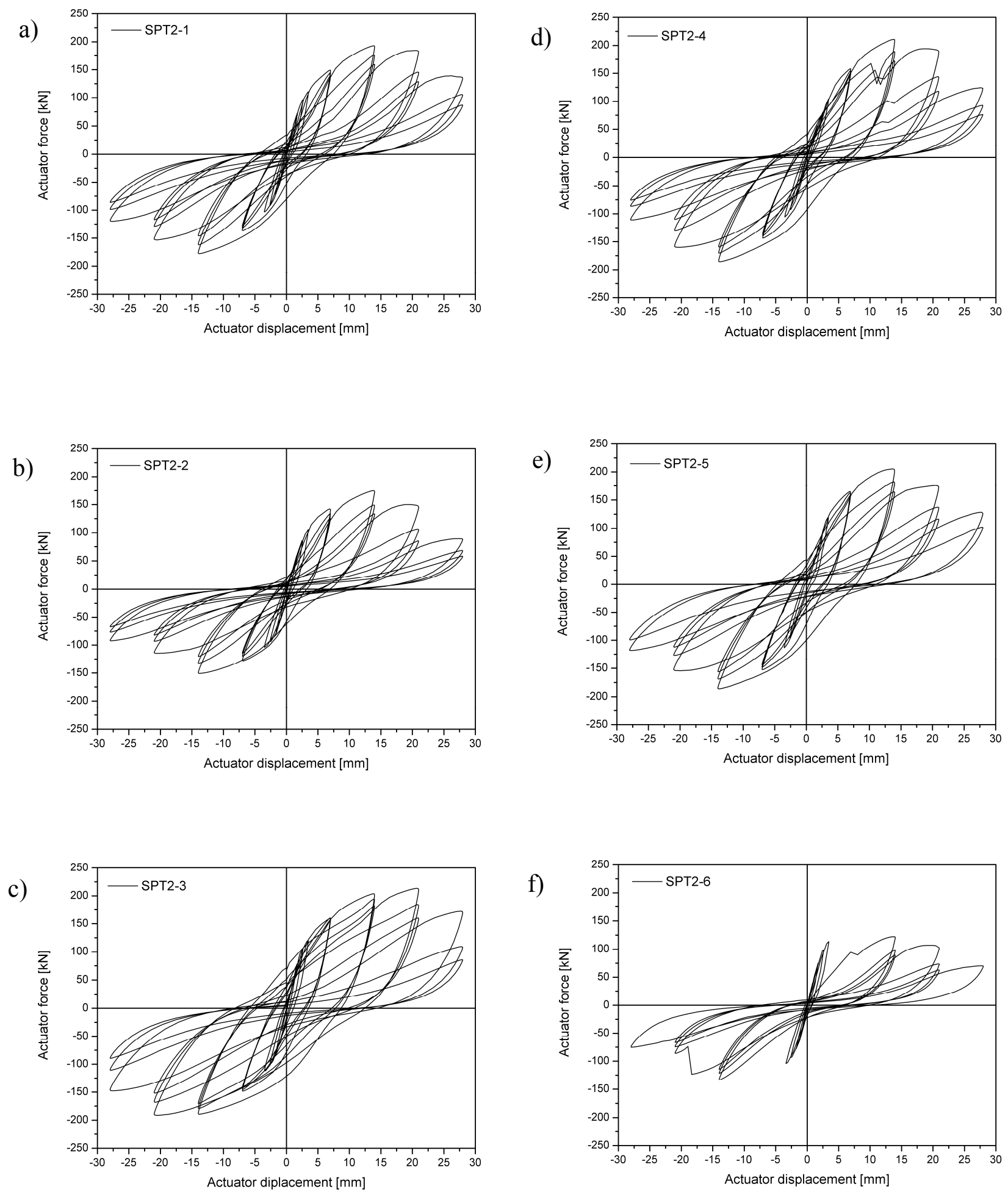

Figure 9: Hysteretic response of slab panel tests; a) SPT2-1, b) SPT2-2, c) SPT2-3,

d) SPT2-4, e) SPT2-5 and f) SPT2-6 


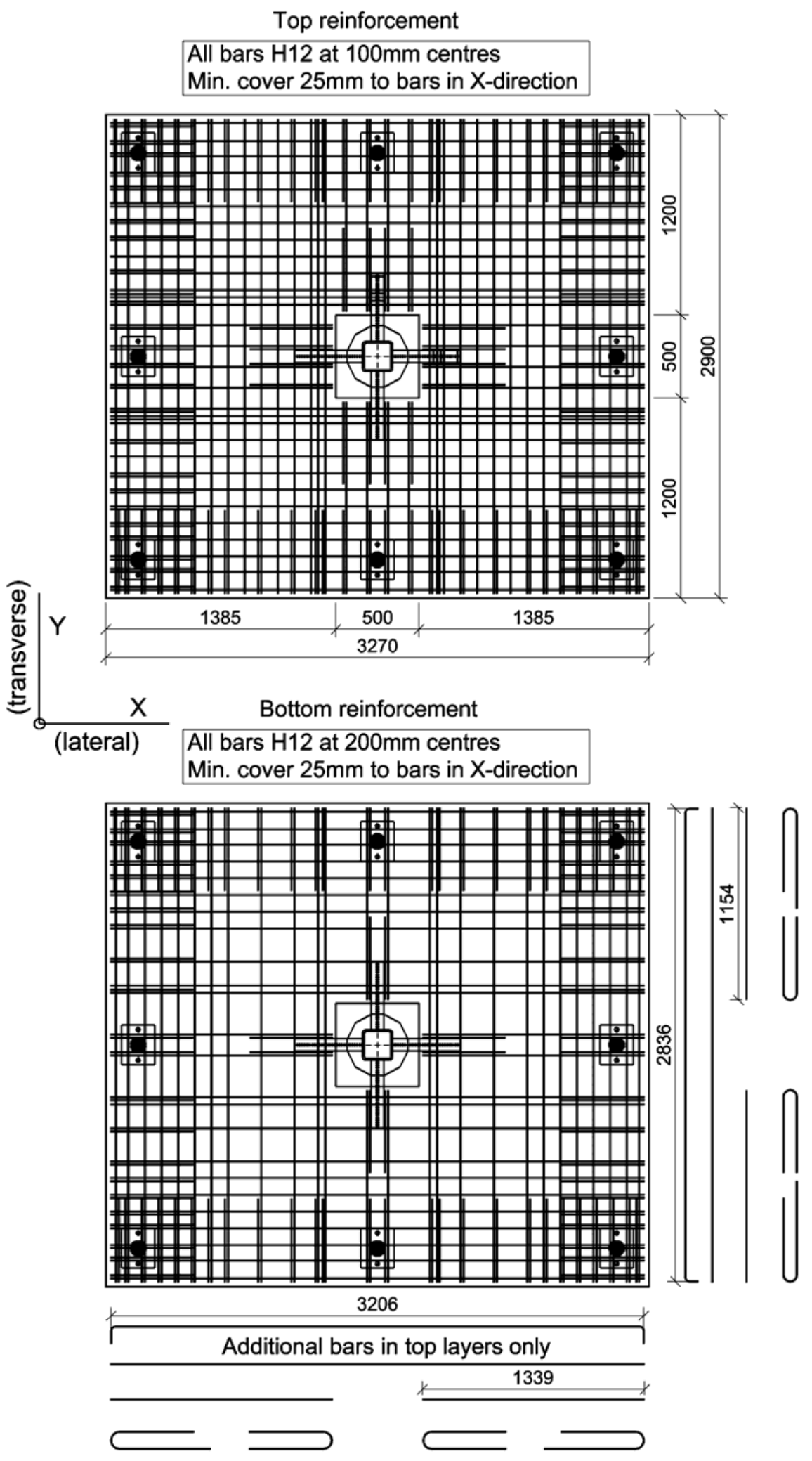

Figure 10: Top and bottom reinforcement in large scale slab tests 


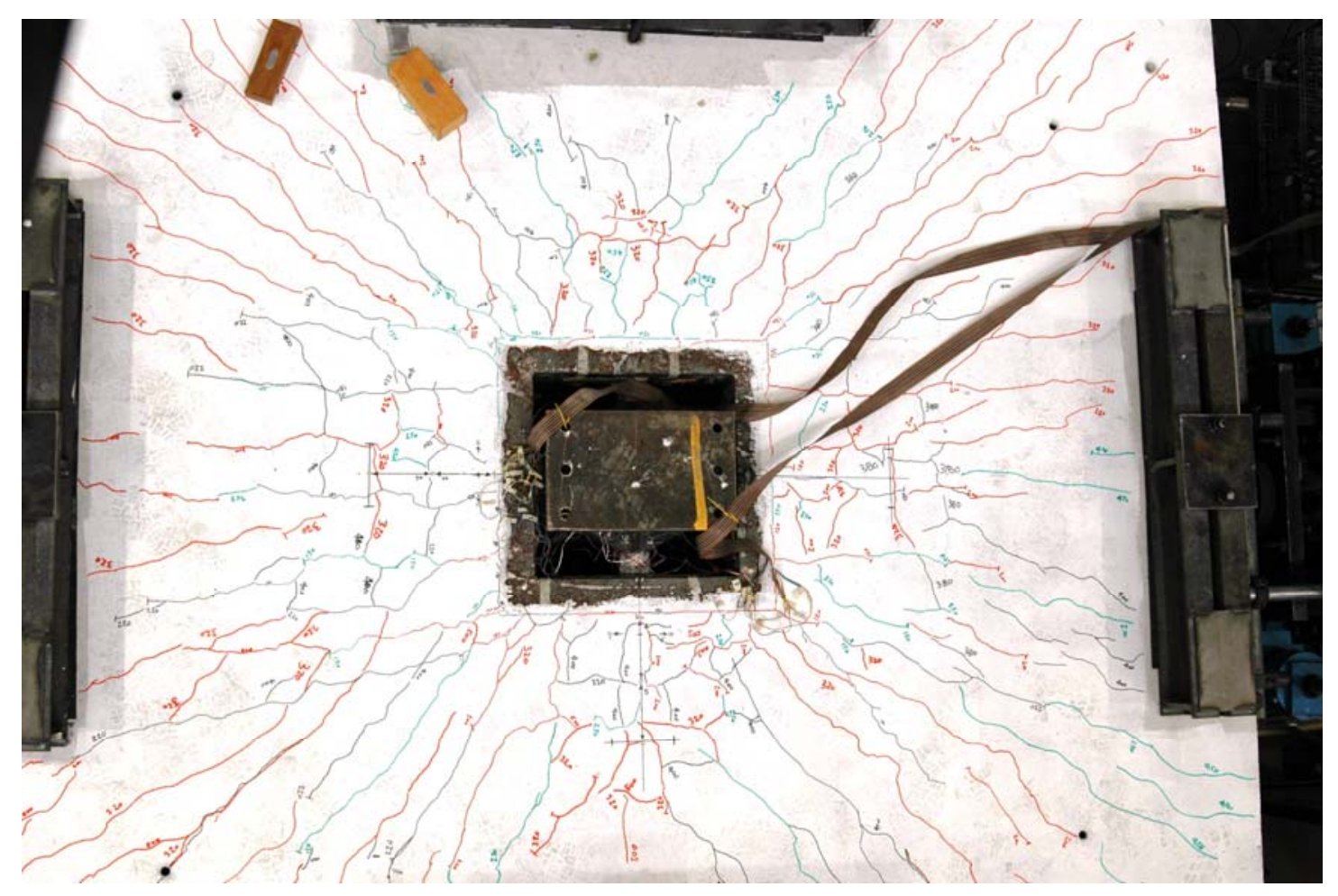

Figure 11: Crack pattern at end of test LS-1 


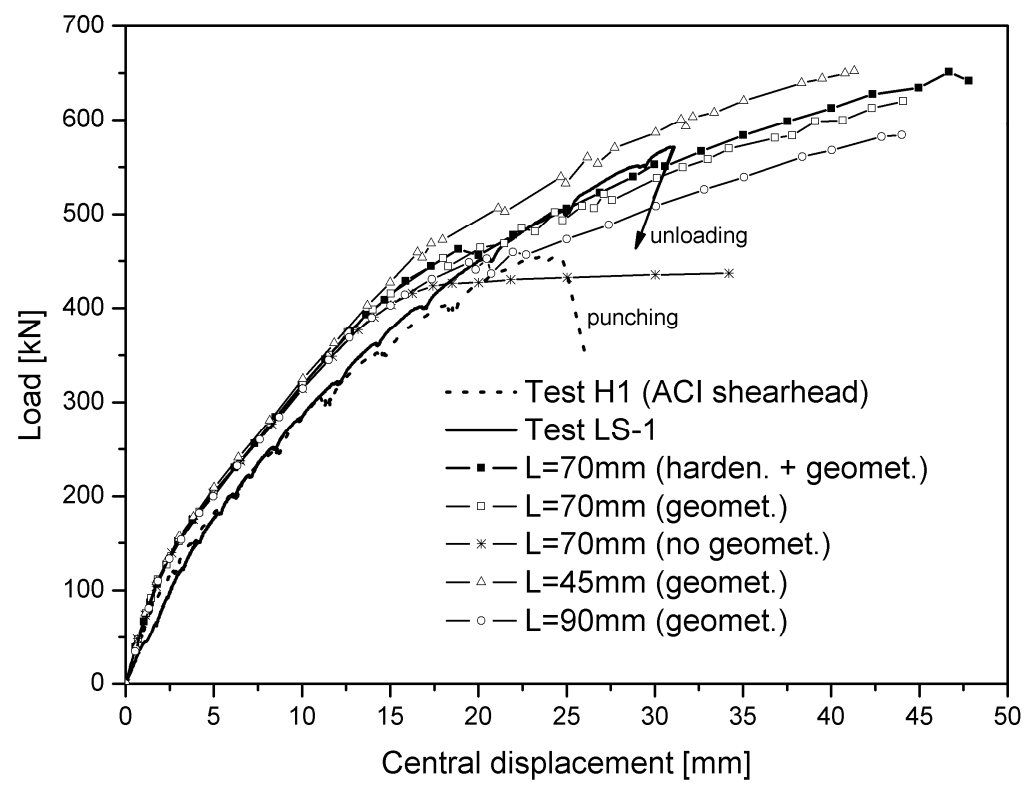

Note: $\mathrm{L}=$ length of exposed shear arm in gap, Fully integrated = specimen H1 [9].

Figure 12: Measured and predicted load displacement curves for gravity tests LS-1 and H1 [9]. 


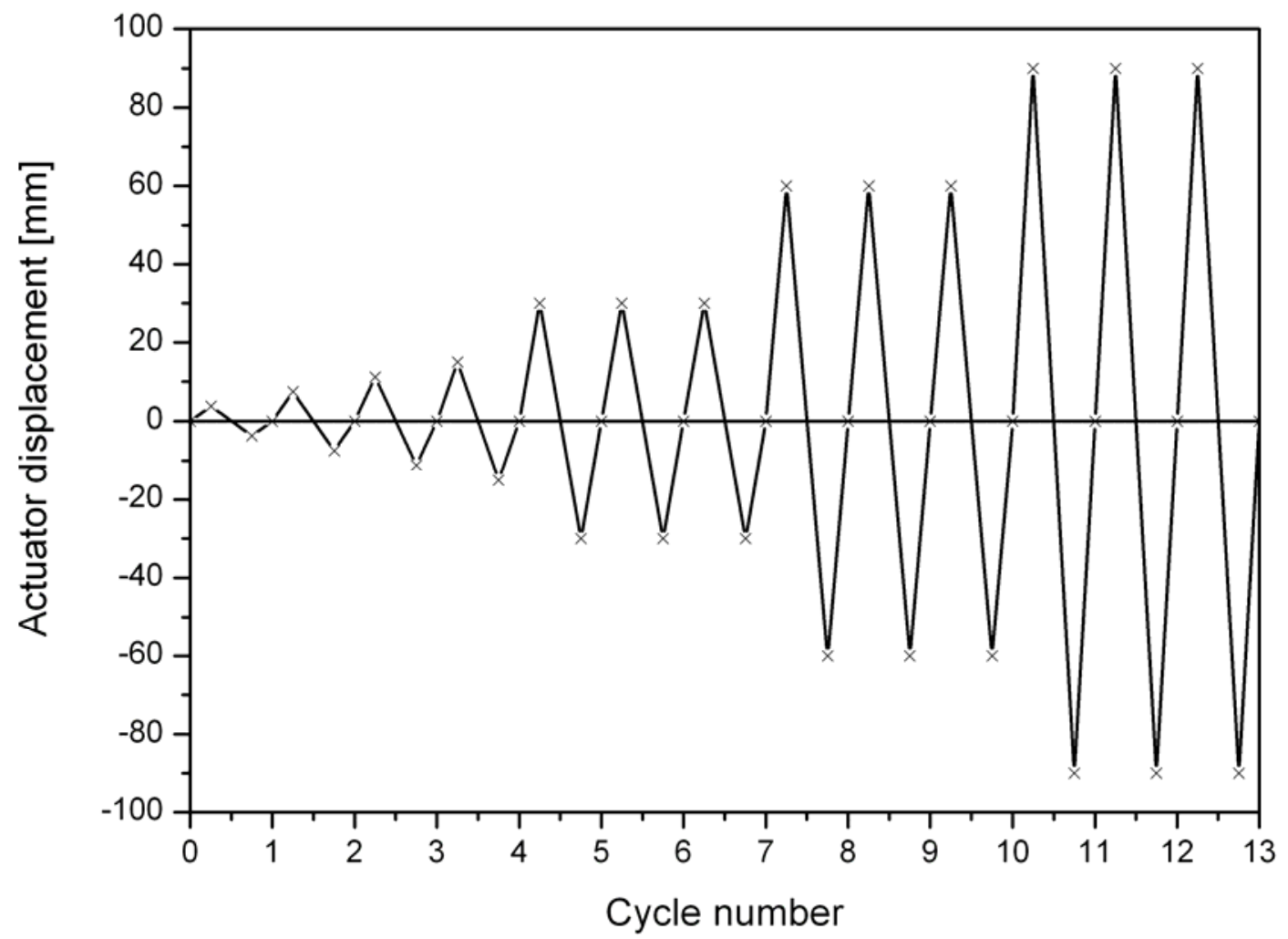

Figure 13: Loading regime for cyclic lateral large scale testing 


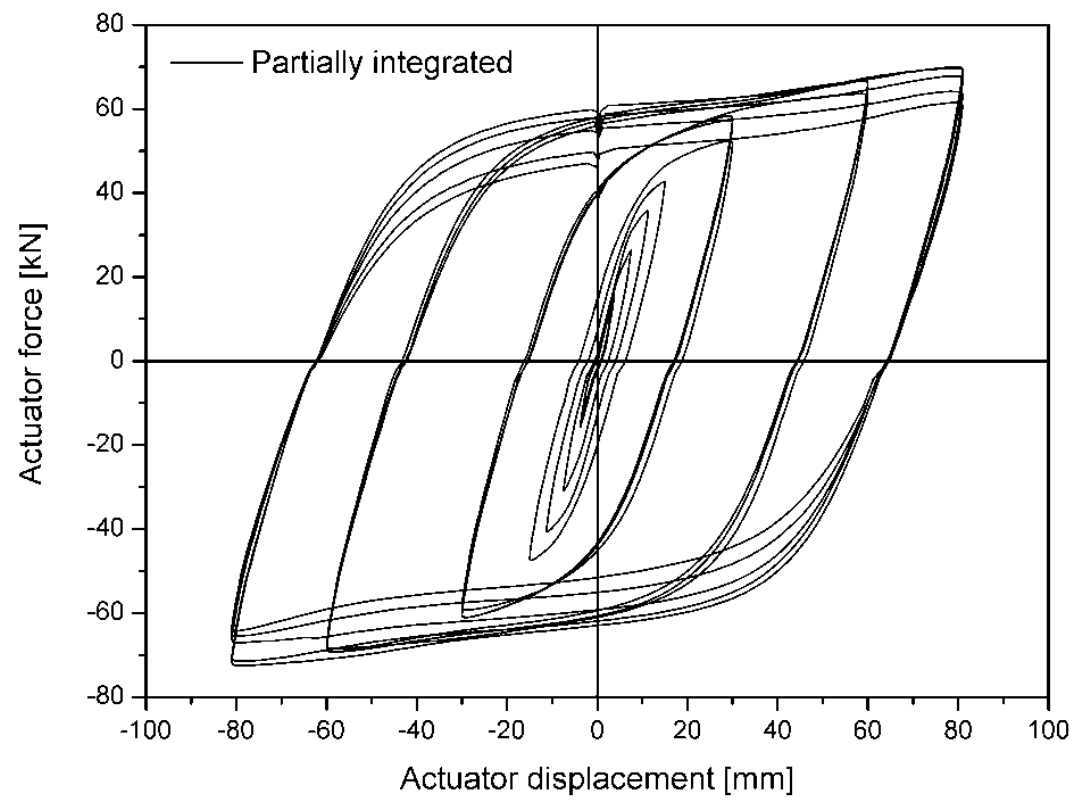

a)

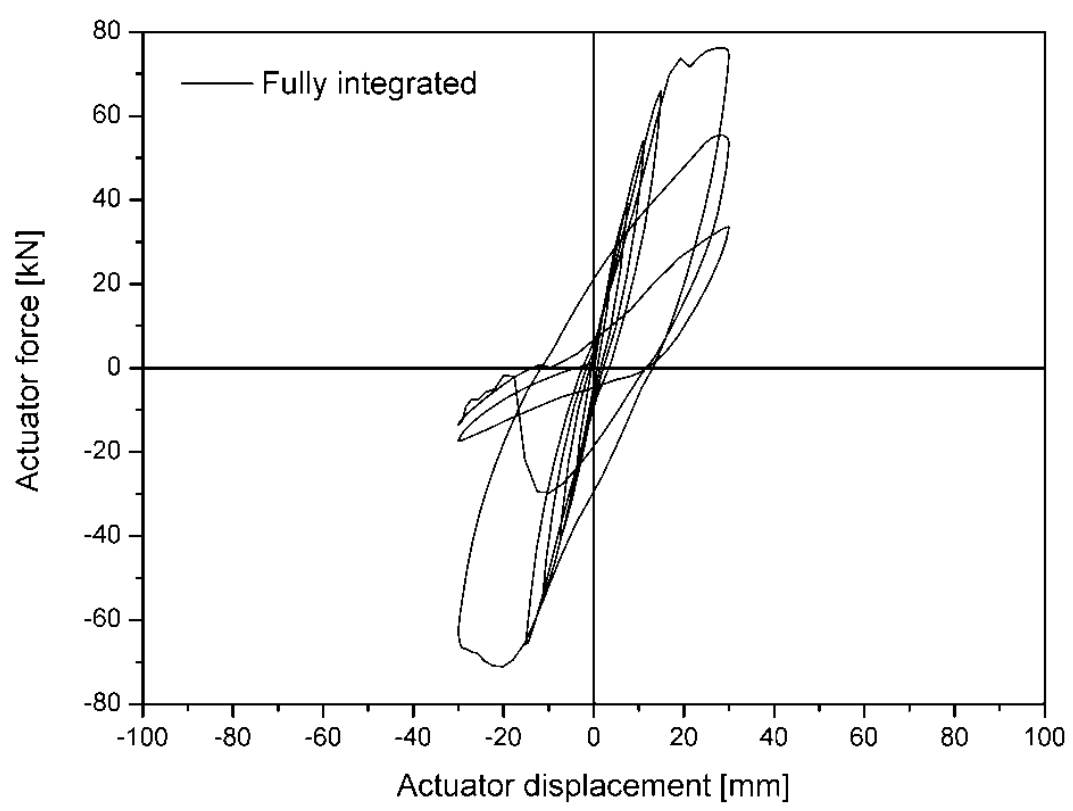

b)

Figure 14: Measured hysteretic responses of a) partially integrated (Test LS-2) and b) fully integrated shearhead (Test H1 [10]) 


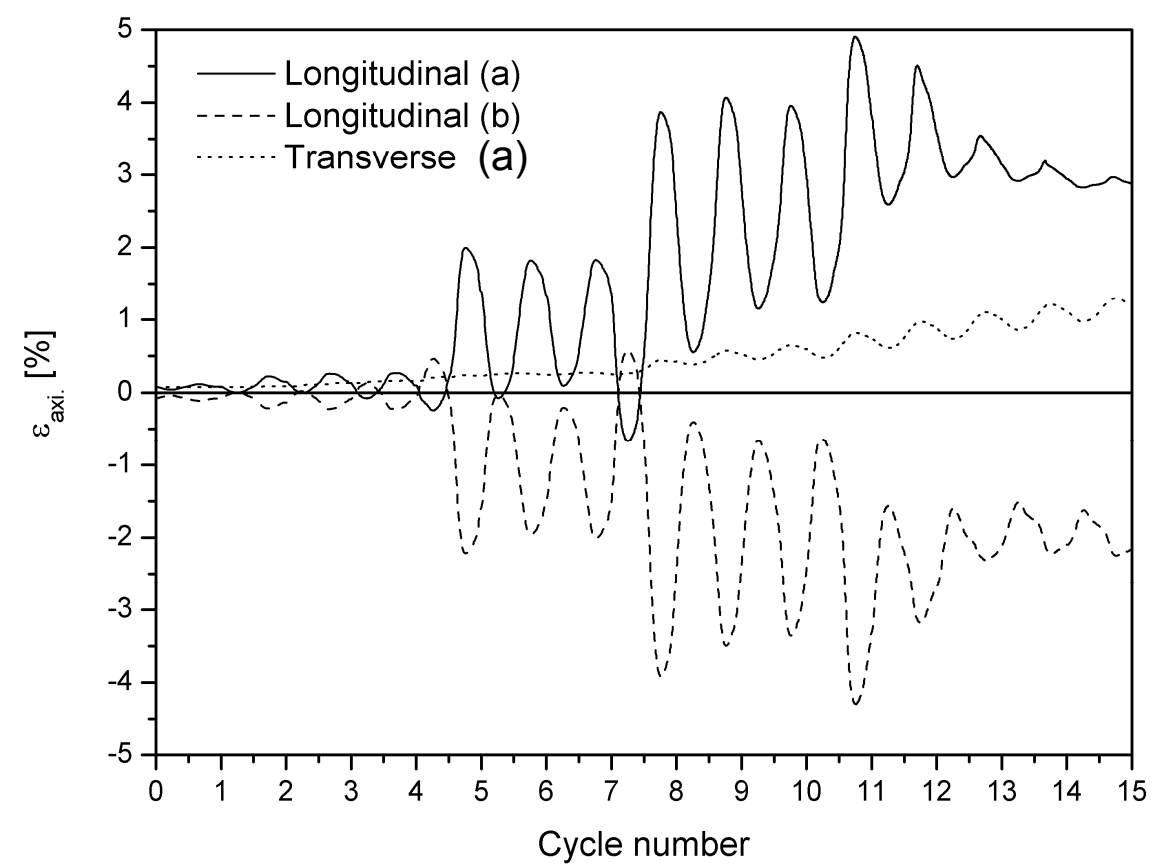

Figure 15: Axial strains measured in top flange of longitudinal and transverse shear arms (a) adjacent to gusset plate and (b) adjacent to collar.

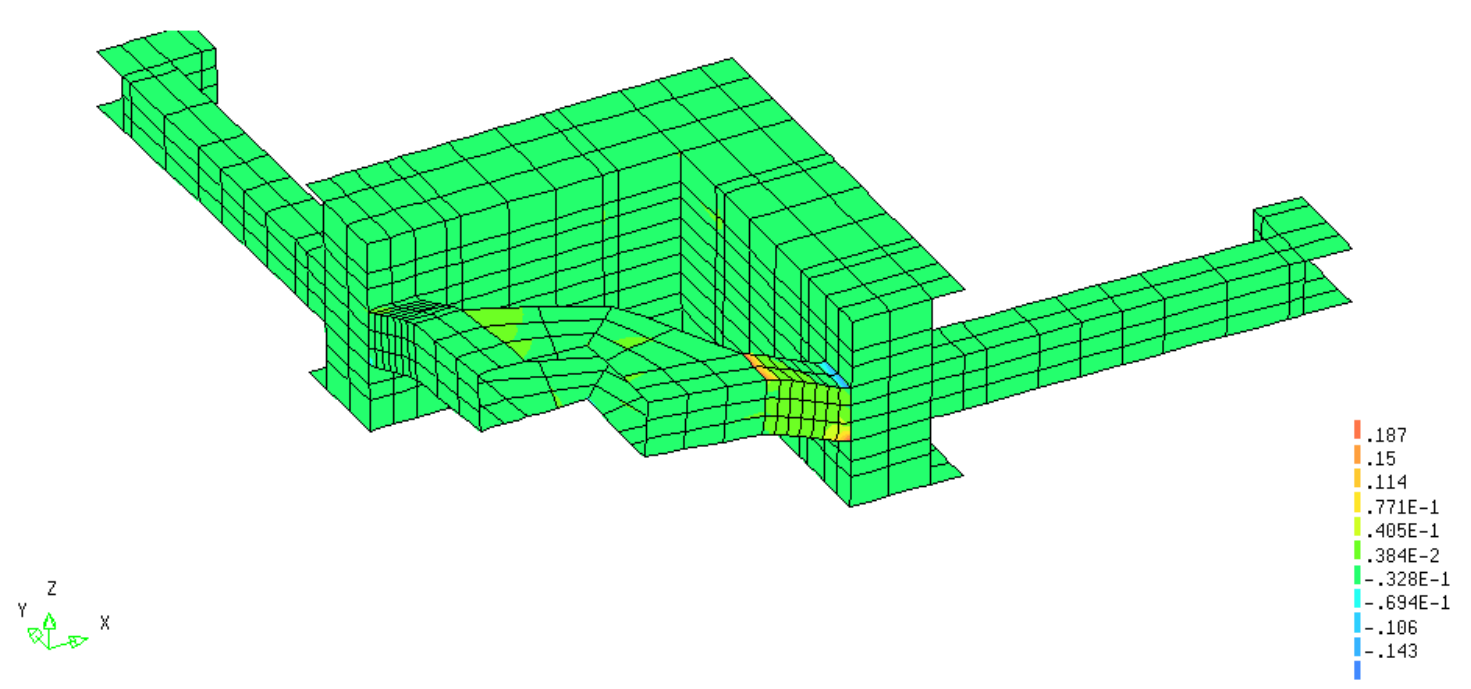

Figure 16: Plastic axial strain $\mathrm{E}_{\mathrm{pxx}}$ contours in longitudinal fuse at ultimate load of $615 \mathrm{kN}$ 


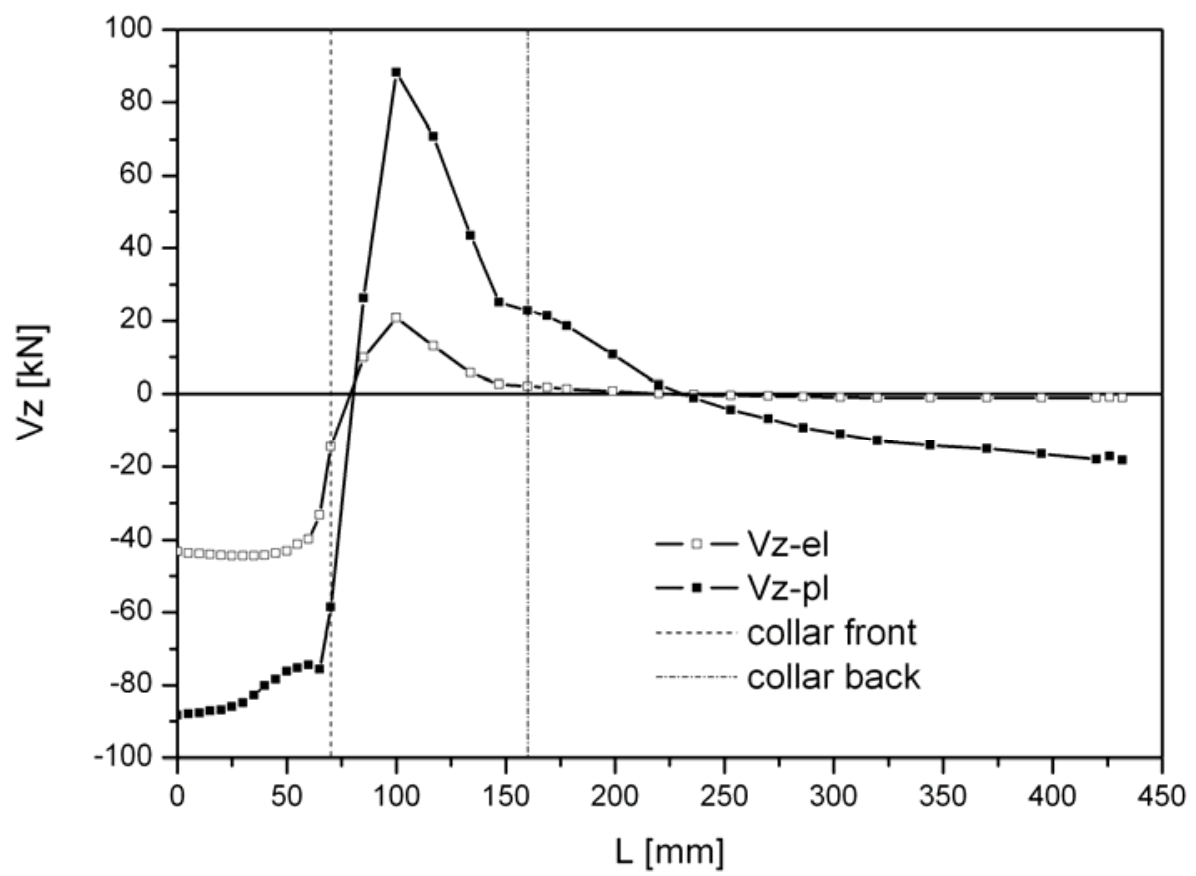

Figure 17: Shear force distribution in web along the shear arm at elastic limit $(180 \mathrm{kN})$ and ultimate $(615 \mathrm{kN})$ loads

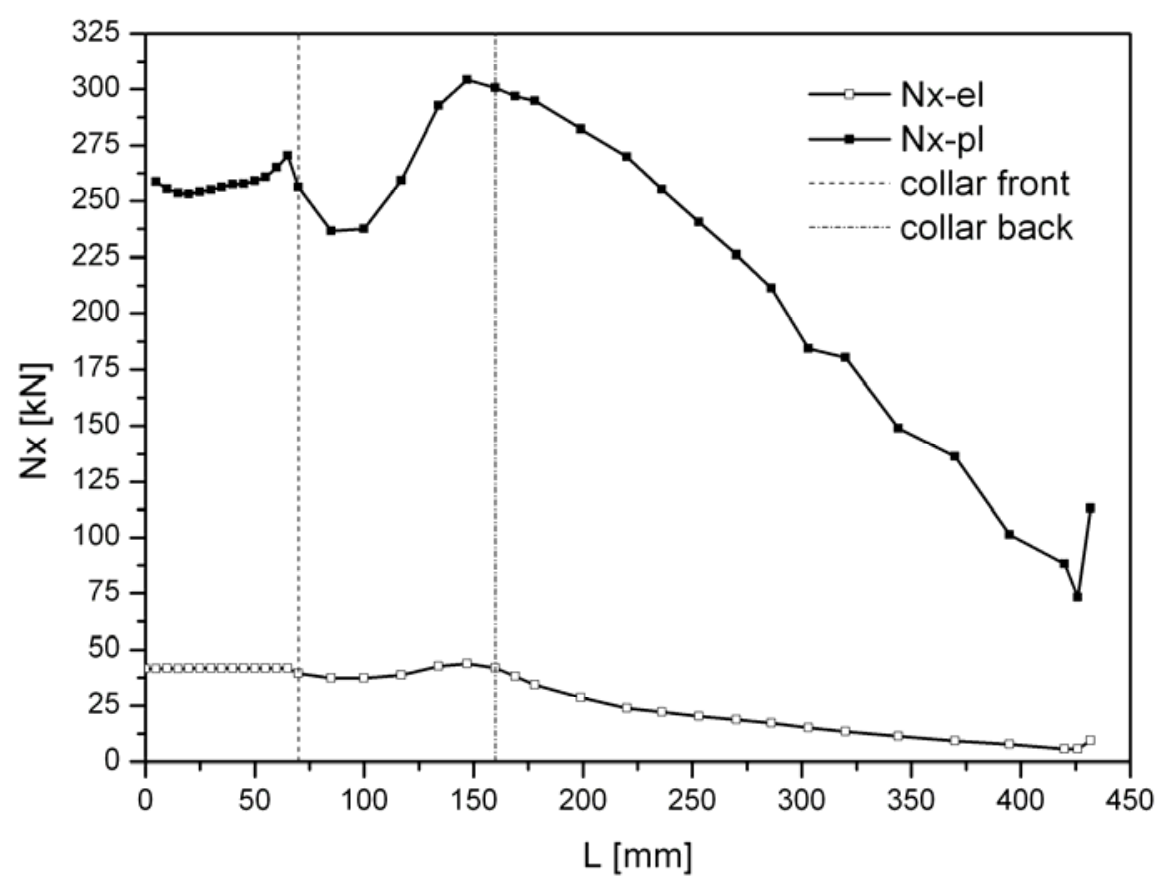

Figure 18: Axial force distribution along shear arm at elastic limit $(180 \mathrm{kN})$ and ultimate $(615 \mathrm{kN})$ loads 


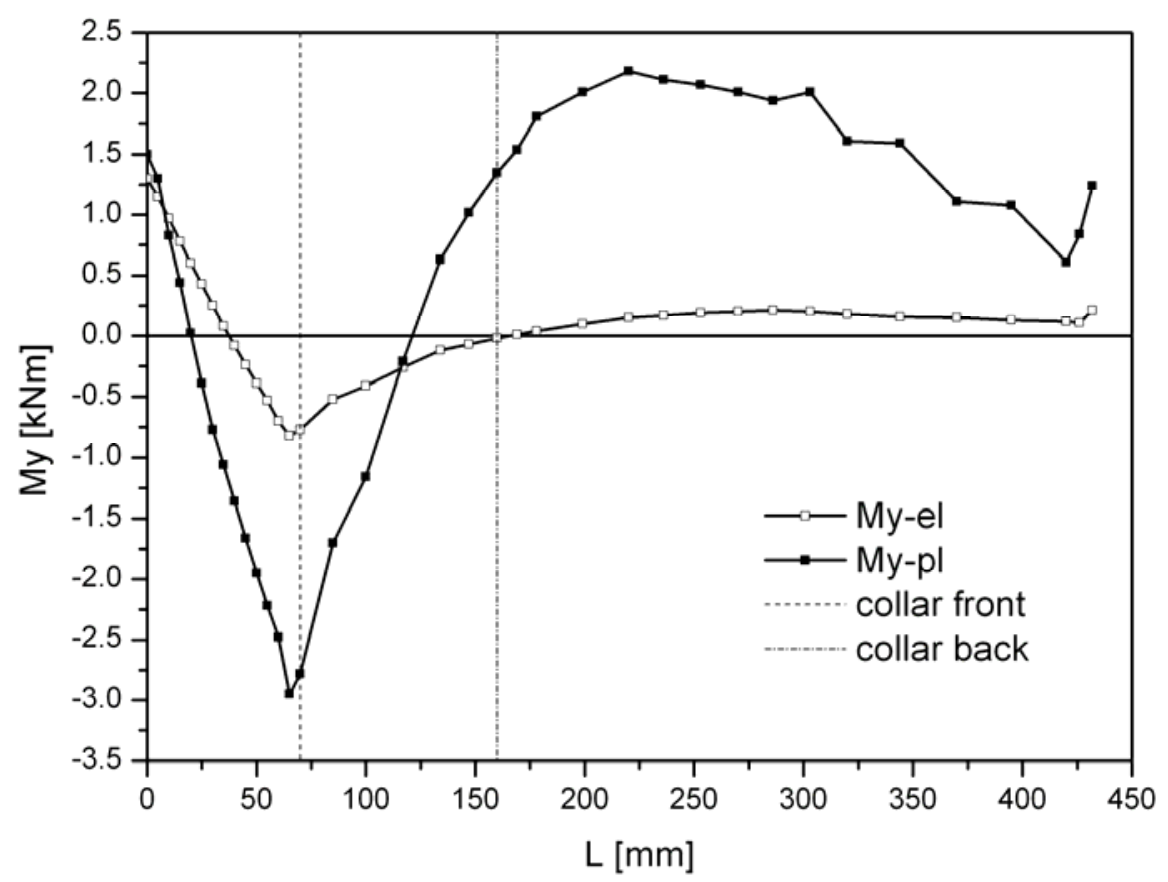

Figure 19: Bending moment distribution along shear arm at elastic limit $(180 \mathrm{kN})$ and ultimate $(615 \mathrm{kN})$ loads

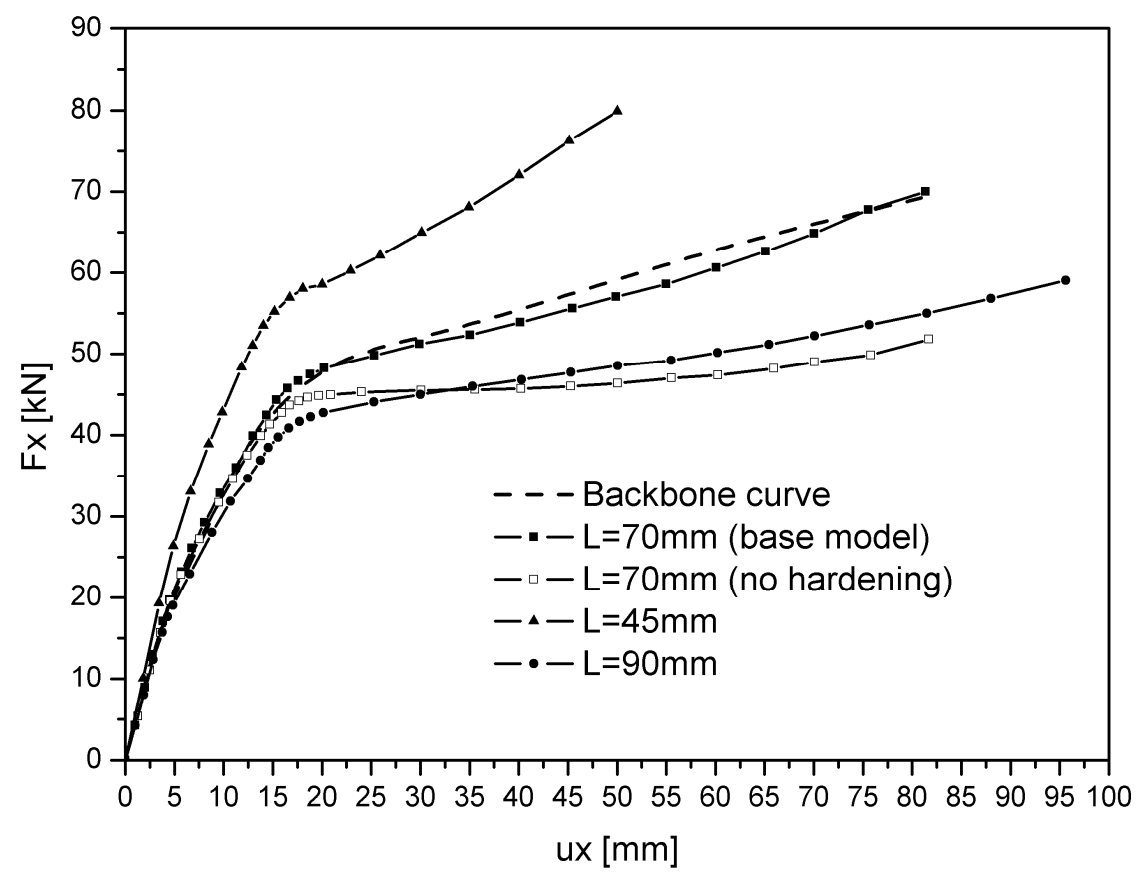

Figure 20: Predicted responses versus backbone curve for Test LS-2. 
Shear failure modes

Mode I

Transversal arm $=$ Longitudinal arm

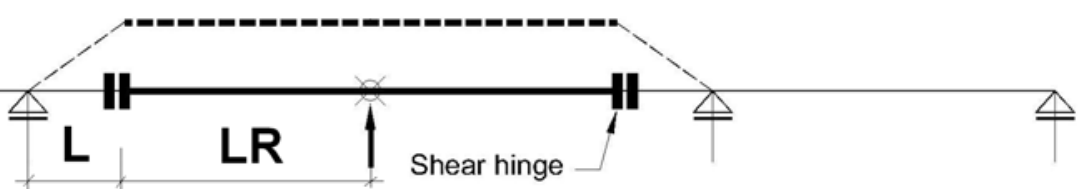

$\mathrm{Fz}$

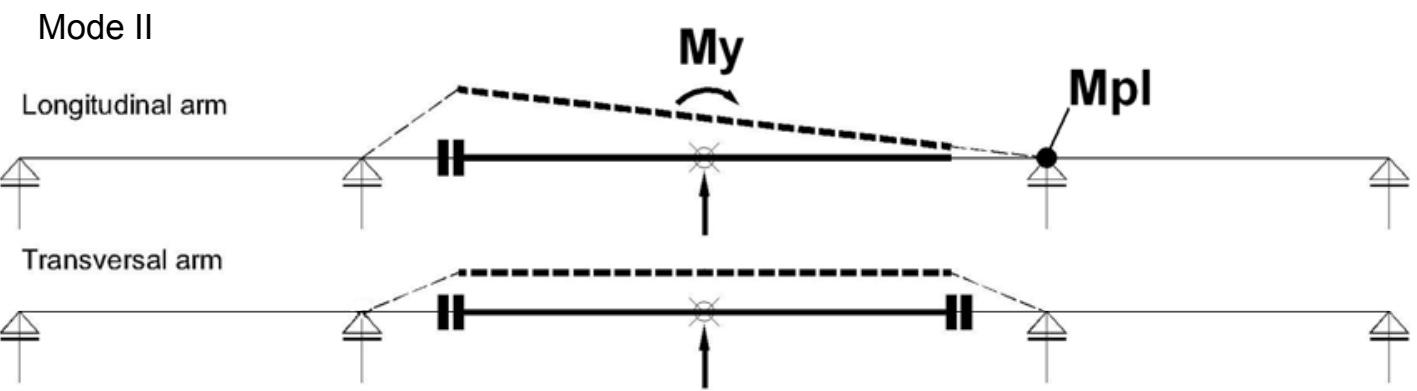

Mode III

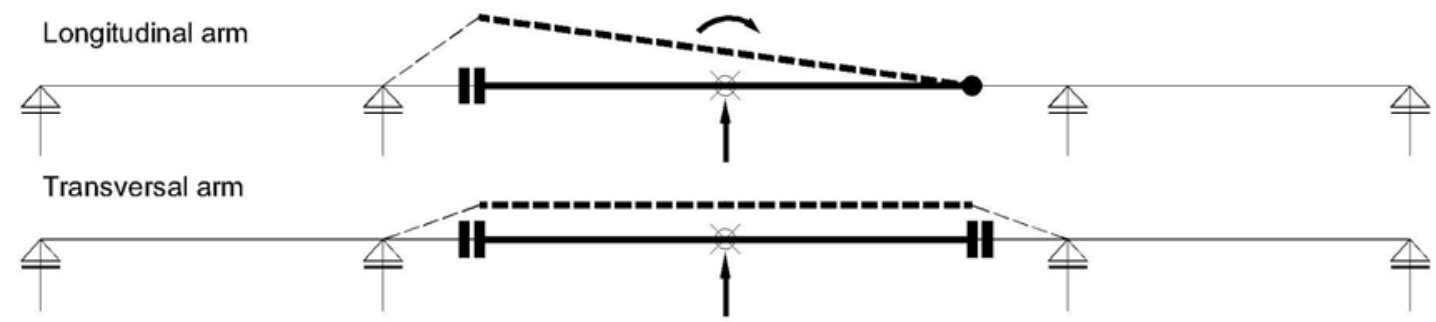

Mode IV

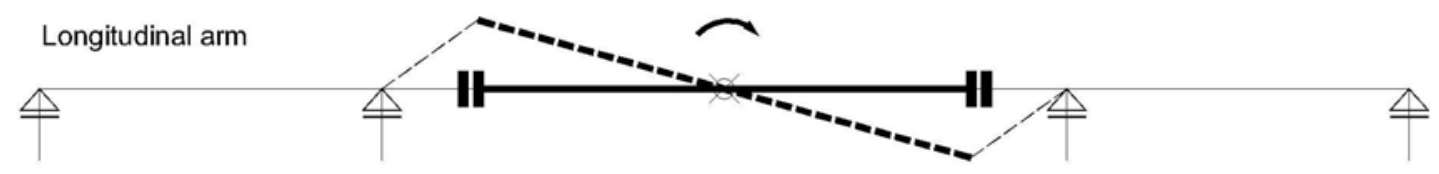

Transversal arm

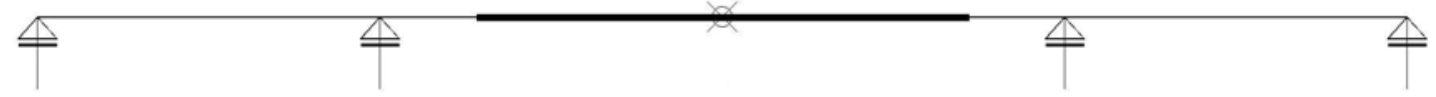

Figure 21: Plastic shear failure modes for shearhead system 


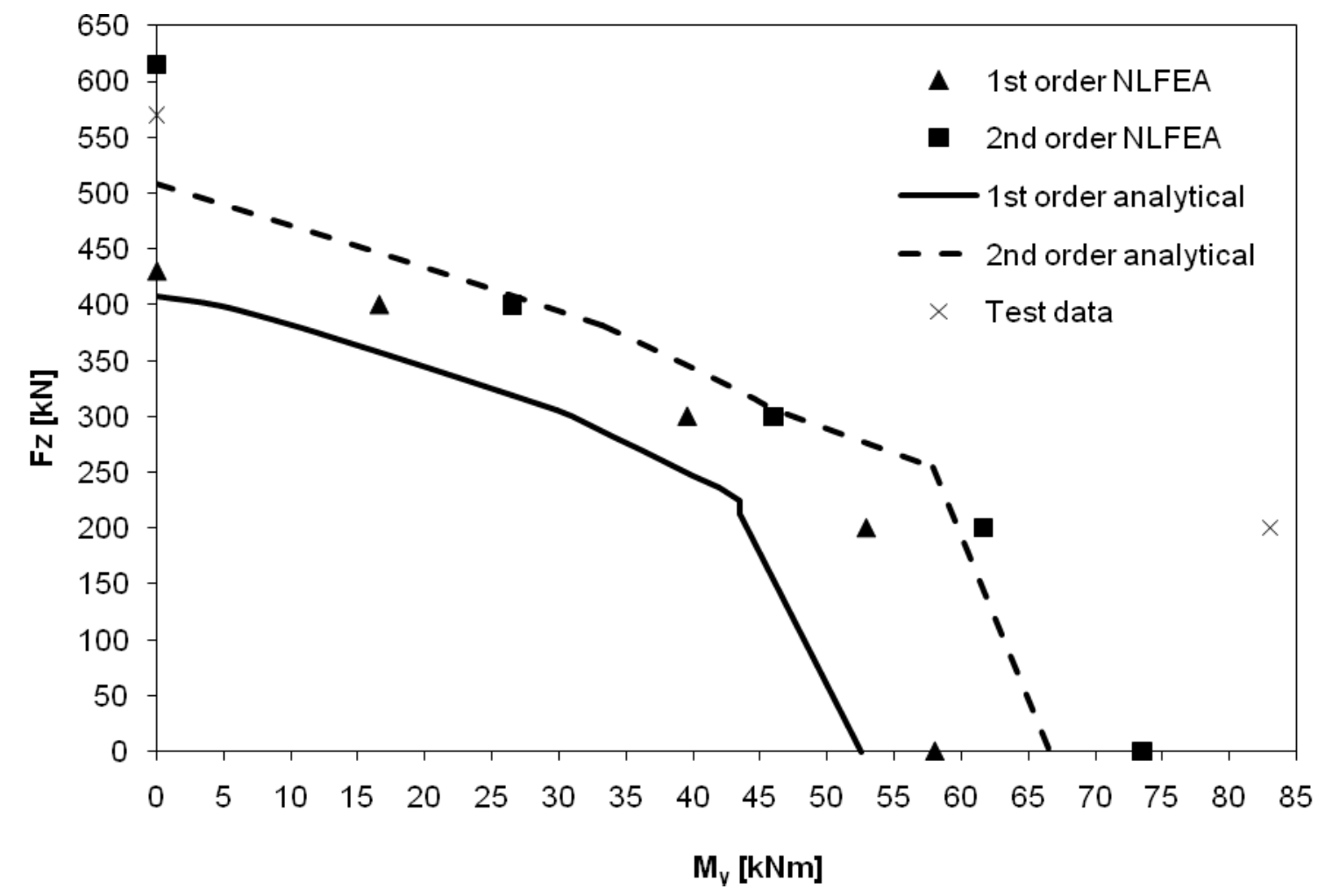

Figure 22: First and second order moment-gravity load interaction diagram 